Volume (2) No. (3) 2019

توظيف انترنت الاشياء في التعليم: المبررات، المجالات، التحديات

أ. دم/ جمال علي الدهشان 


\section{توظيف انترنت الاشياء في التعليم: المبررات، المجالات، التحديات}

$$
\text { أ. دا دمال علي الدهشان }
$$

أستاذ أصول التربية، وعميد كلية التربية، جامعة المنوفية، مصر،

gamal.eldahshan@edu.menofia.edu.eg

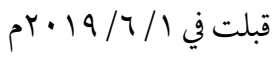

g_eldahshan@yahoo.com

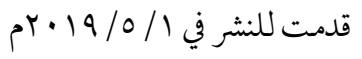

الملخص: يشكل إنترنت الأشياء ظاهرة جديدة لتوظف الانترنت في مختلف تطبيقات الحياة، وأصبحت واقع لمستقبل لم تكتمل معالمه بعد ولم تتشكل القاعدة الصلبة لانطلاقته المرتقبة، وهو ما ستجلبه التكنولوجيا للبشرية، فهل نحن مستعدون له؟ تسعى الورقة الحالية المي استكشاف ظاهرة انترنت الأشياء وتطبيقاتها في الحياة العملية بشكل عام وفي التعليم بشكل خاص، وتحاول الورقة استيضاح النقاط التالية:

$$
\text { - - المقصود بإنترنت الاشياء وخصائصه ومجالات تطبيقه }
$$

- - المبررات التي تدعو المى ضرورة الاستفادة من تقنية انترنت الاشياء في المجال التعليمي - - مالمجالات التي بمكن استخدام انترنت الأشياء فيها لتطوير خدمات وأنشطة المؤسسات

$$
\text { التعليمية. }
$$

- - التحديات التي تواجه استخدام انترنت الاشياء في بجال التعليم. الكلمات الدلالية: انترنت الاشياء، التوظيف في التعليم، البيانات الضخمة 


\title{
Employing Internet of Things in Education: Justifications, areas, challenges
}

\author{
Gamal Ali El-Dahshan \\ Professor of "Foundation of Education", and Dean, College of Education, Menoufia \\ University, Egypt \\ g_eldahshan@yahoo.com \\ gamal.eldahshan@edu.menofia.edu.eg
}

Received 1 May 2019

Accepted in 1 June 2019

\begin{abstract}
Internet of things is a new phenomenon to employ the Internet in various applications of life, and became a reality for the future is not yet complete and did not form the basis of the solid start of the upcoming, which will bring technology to humanity, are we ready for it? The paper seeks to explore the phenomenon of Internet objects and their applications in working life in general and in education in particular, and the paper tries to clarify the following points:
\end{abstract}

- The Internet means things and their characteristics and areas of application

- Justifications that call for the need to take advantage of Internet technology in the field of education

- Areas in which Internet objects can be used to develop the services and activities of educational institutions

- The challenges facing the use of Internet stuff in the field of education.

Key words: Internet of Things, Employing in Education, Big Data. 
عاش العالم في ثمانينيات وتسعينيات القرن الماضي في عصر الحوسبة والحواسب المكتبية و الشخصية، وكانت هذه الموجة التي استمرت في أوجها لمدة 10 سنة تقريبًا هي طابع ذلك العصر، ومع تطور المعالجات والشاشات انتقلنا إلى عصر التجوال Mobility حيث شكل ظهور الآي فون في

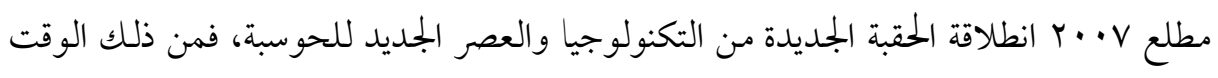
وحتى اللحظة ونحن نحمل ما يستطيع القيام بمهام تفوق تلك التي يقوم بها حاسب مكتبي ضخم يقبع على مكاتبنا قبل · اسنوات. مما لاشك فيه أننا سنعيش في عصر الأجهزة المحمولة لعدة سنوات قادمة، ولكن هناك موجة ضخمة قادمة وبدأت تصلنا بعض من ملامعها منذ سنوات قليلة، نحن علئ وشك أن نعيش ما بات يعرف بعصر " إنترنت الأشياء" Internet Of Things أو ما يعرف اختصارًا ب IOT. فتقنية الإنترنت غيّرت عالمنا كله، وسمحت لنا بالتواصل مع بعضنا البعض، فأصبح تبادل

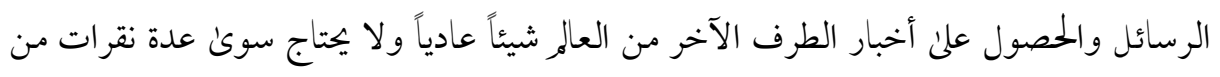

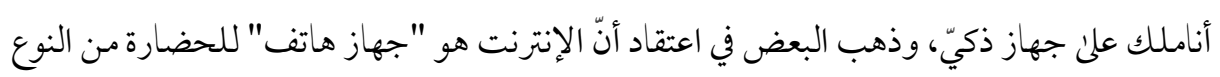
الأول، يربط كافة أنحاء الكوكب ببعضه، ويجوله لقريةٍ صغيرة.

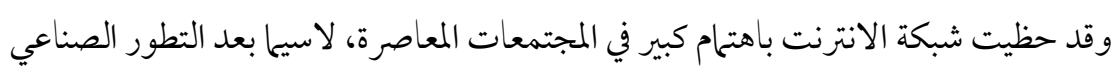
المهول في تصنيع وتطوير "الاشياء - Things "- باسم "الثورة الصناعية المقبلة" - التي لها القابلية

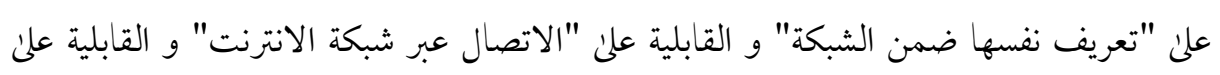
"التفاعل مع الاشياء الاخرى المرتبطة بالإنترنت"، باسم "الثورة الصناعية المقبلة"، واصبحنا على لئل وشك أن نعيش ما بات يعرف بعصر " إنترنت الأشياء Internet Of"Things أو ما يعرف اختصارًا

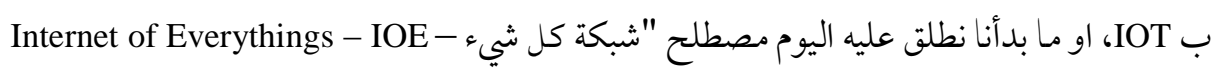
" ايضا، حيث تهدف جميعها لإنشاء بيئة افضل لحياة الانسان. 
لقد أصبح تعبير (IoT) " إنترنت الأشياء "). واحدًا من أكثر التعابير المألوفة والرائجة بين مختلف قطاعات الأعمال والتقنيات في الفترة الأخيرة، لم يأت من فراغ، بل تبرره وتدعمه الأرقام والوقائع، حيث نستطيع اليوم استخدام حلول إنترنت الأشياء لأتمتة ومراقبة كل شيء قد تتخيله، فمثلًا، يمكن تشغيل مكيفات الهواء وإنارة غرفة الاجتحاعات تلقائياً بمجرّد استشعار هاتفك الجورال من علن مسافة معينة، أو يمكن أن توعز لسيارتك بتشغيل حاسوب مكان عملك، ما أن تصبح على لم مسافة ه دقائق من مكتبك.

وانترنت الاشياء هو مفهوم متطور لشبكة الإنترنت بحيث تمتلك كل الاشياء في حياتنا قابلية الاتصال بالأنترنت أو ببعضها البعض لإرسال واستقبال البيانات لأداء وظائف محددة من خلال الشبكة، ويُفترض بهذه التكنولو جيا أن تجعل حياتنا أبسط تتحسين حالتنا بها، من خلال ربط العديد من الأشياء المتنوعة والمتعددة عبر وسائط استشعار، والتحكم بها من خلال الانترنت، حيث يمكن ان تتفاعل الاشياء مع بعضها البعض من جهة ومع الانسان من جهة اخرئ لتيح بذلك العديد من التطبيقات الجديدة في المجالات الطبية، والصناعية، والاقتصادية، والتربوية، والرياضية وحتى على مستون الحياة اليومية للفرد، فأساس الموضوع يعتمد علن سيناريو تفاعل الاشياء عبر الانترنت لتوفير

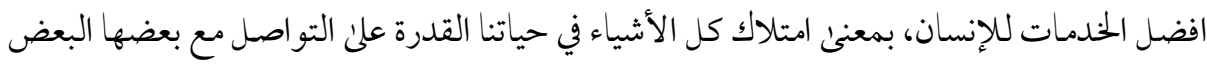
أو مع شبكة الإنترنت لأداء وظائف محددة خاصة بها أو نقل البيانات بين بعضها البعض من خلال بعض المستشعرات الخاصة المرتبطة بها. ويتم ربط "الاشياء" بشبكة الانترنت من خلال استخدام احدى التقنيات الحديثة للربط بالشبكات كتقنية البلوتوث، تقنية ZigBee، تقنية Wi-Fi، تقنية الجيل الرابع G\& او غيرها، وما احدثثه هذه التقنيات من تحول جذري في بناء شبكات الحساسات اللاسلكية Wireless) sensors (Networks - WSNs وتشير التقارير الصادرة من شركة سيسكو وشركة اريكسون وغيرهما من الشركات الرائدة في مجال تكنولوجيا المعلومات انه من المتوقع ان يكون هناك عب مليار جهاز متصل بالإنترنت بحلول 
عام • r · r كما انه سيكون عدد الأجهزة المتصلة بإنترنت الأشياء ع مليار جهاز أي إن معدل نموها يفوق النمو المحتمل لعدد سكان العالر بأكثر من سبعة أضعاف، وسوف يتم إنفاق ما يقرب من 1 تريليون دولار ضمن إنترنت الأشياء علن مدئ السنوات الخمس المقبلة وستكون الشركات والمؤسسات المتبني الأكبر لحلول إنترنت الأشياء، وسيستثمر قطاع الأعمال • م مليار دولار في تقنيات إنترنت الأشياء خلال الخمس سنوات القادمة، •9 ٪ منها سيذهب للاستثمار في الأنظمة

$$
\text { والبريجيات التي تشغل هذه الأجهزة. }
$$

كما يتوقع أن تصل إيرادات سوق إنترنت الأشياء إلى أكثر من ..7 مليار دولار في عام

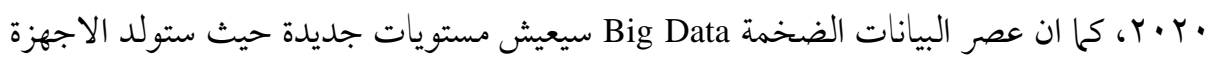
في عالم إنترنت الأشياء بحلول • · · r ما يزيد عن · ع ألف إكسا بايت من البيانات، • ع ألف إكسا بايت = • ع تريلليون جيجا بايت، وهي المساحة التي تكفي لتسجيل كل الكلام الذي نطق به البشر

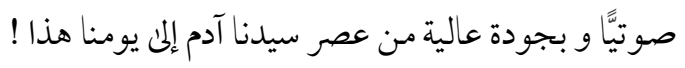
كما تؤكد تلك التقارير ان انترنت الاشياء شئنا أم أبينا ستدخل حياتنا وبيوتنا، وستغير كل ما حولنا المن نظام بيئي من المعلومات، وبذلك تغيير طريقة حياتنا،ـ فمن الثلاجات والسيارات إلى ساحات وقوف السيارات والبيوت، يأتي إنترنت الاشياء بمزيد من الابتكارات، التي تنضم إلى التكنولوجيا الرقمية المستخدمة في حياتنا اليومية، وستكون هي القاعدة في ما نفعله. والسؤال هو كيف ستؤثر في عالمنا، وهل تغير طريقتنا في التفاعل مع بعضنا البعض، وما موقف نظامنا التعليمي ومؤسساته التربوية والجامعية من تطبيقات تلك التقنية في تقديم تعليم يتفق وطبيعة العصر الذئ نعيشه في الوقت الحاضر وفي المستقبل وتقديم حلول غير تقليدية ومبتكرة لمشكلاته وتحدياته ؟. وقد تبنّت عدد من دول الشرق الأوسط مبادرة إنشاء ( مدن ذكية" لعبت فيها الكيانات الحكومية وشبه الحكومية دورًا في فحص تقنيات حلول إنترنت الأشياء المتوفرة، حيث تأتي دولة الإمارات العربية المتحدة والمملكة العربية السعودية في طليعة الدول المستثمرة في بجالات استخدام 


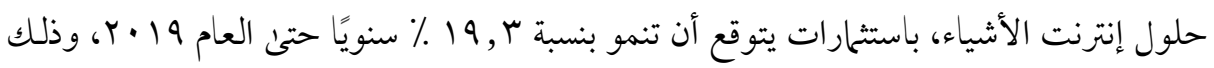

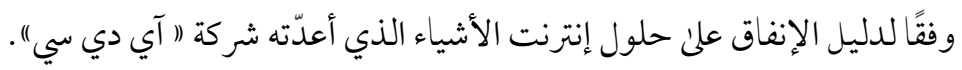

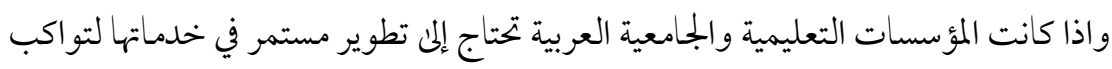

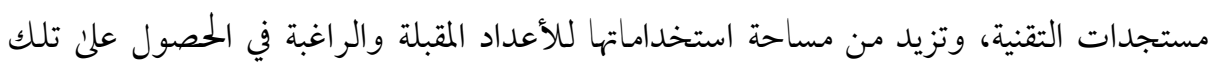

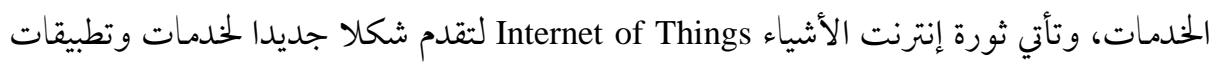

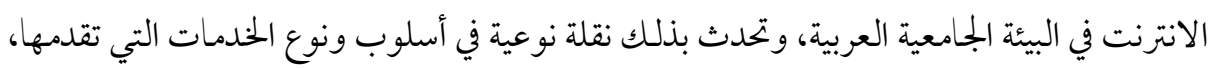

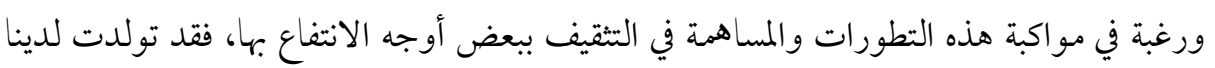
الرغبة في القيام بدراسة علمية للتعريف بتلك التقنية وتطبيقاتها وكيفية توظيفها في مجال التعليم

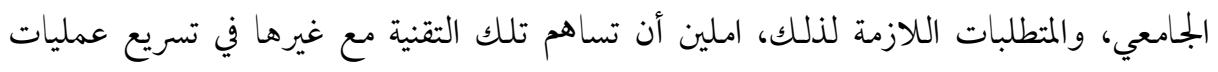

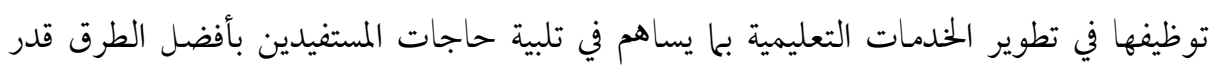
الامكان.

فعلن الرغم من احتلال تقنية إنترنت الأشياء (IoT) مكانة اساسية في كل القطاعات في العاله

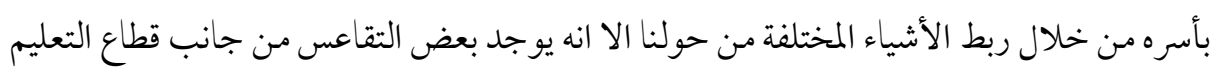

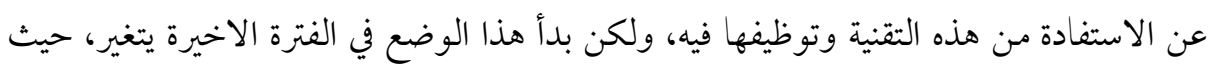

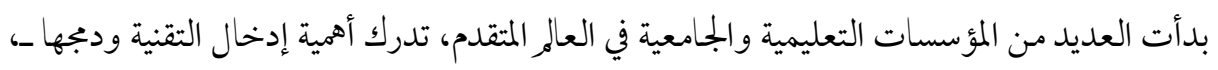

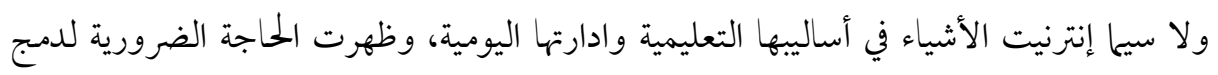

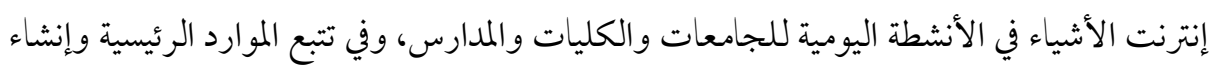

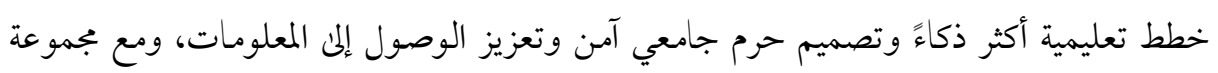

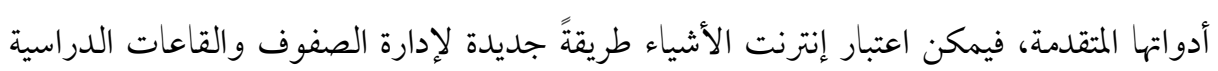

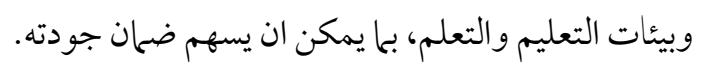
فإنترنت الأشياء تتمتع باعتبارها طريقة جديدة لإدارة الفصول الدراسية باستئه باستخدام أدوات

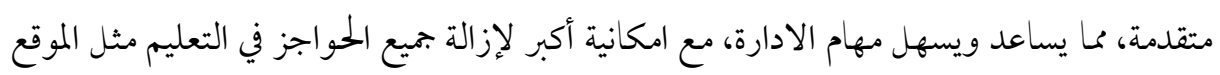


الجغر افي والجغرافيا واللغة والوضع الاقتصادي، فمزيج من التكنولوجيا ييعل التعلم بشكل أسرع

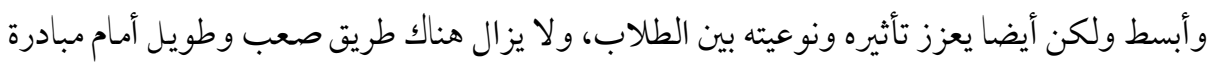
إنترنت الأشياء لتحقيق مزيد من التحو لات في المؤسسات التعليمية.

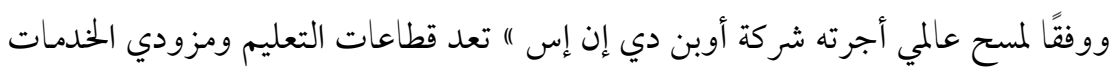

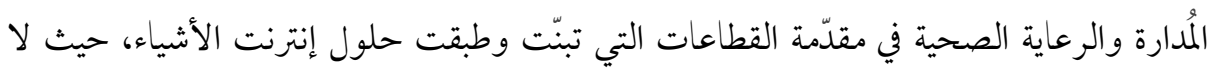

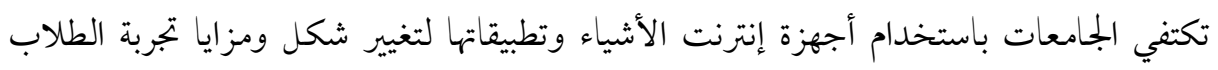

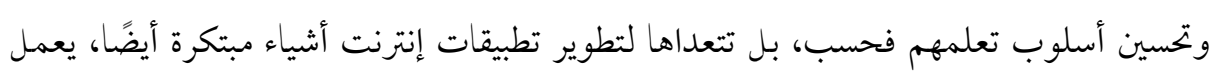
عليها كل من الطلاب والجامعة معًا، ويمكن لصناعات أخرى الاستفادة منها.

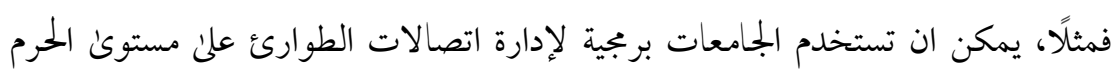

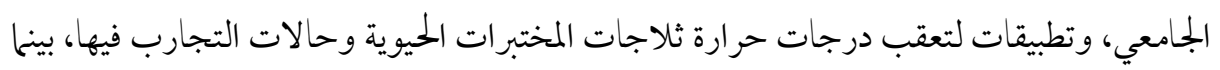
يستخدم الطلاب هو اتفهم الذكية لمعرفة الغسالات الشاغرة في مساكن الجامعة.

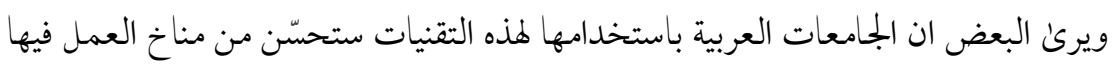

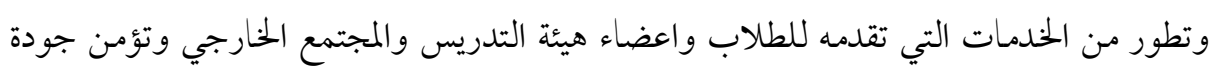
حياة أفضل لهم. كما ان استخدم مزودو الخدمات المُدارة أجهزة إنترنت الأشياء الجامعات العربية في مر اقبة

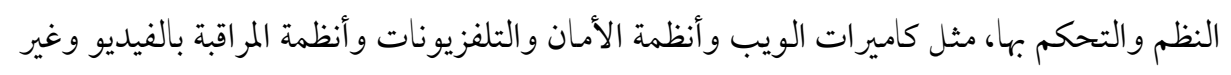

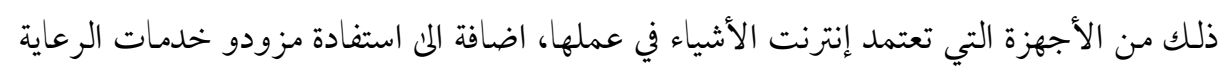

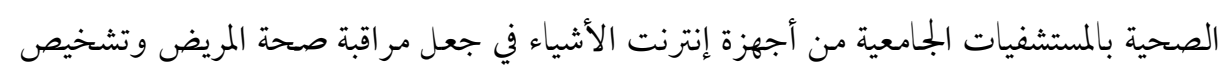

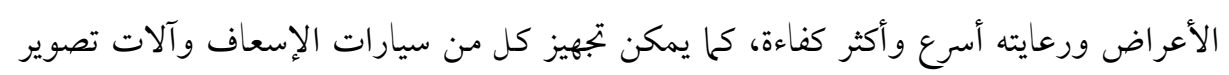

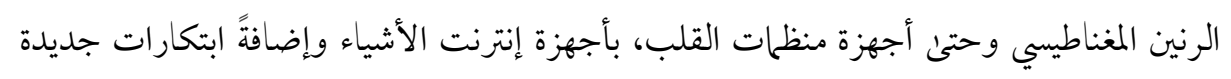
مثل كبسو لات دواء متصلة بالإنترنت تساعد المرضى علن تناول أدويتهم في الأوقات المحدّدة. 
وتستخدم العديد من القطاعات الأخرى إنترنت الأشياء، مثل مبيعات التجزئة، والخدمات المصرفية، والضيافة، والبنئ التحتية للطاقة الكهربائية، لزيادة كفاءتها وشفافيتها في عمليات الأعمال. فمثلًا، تتوفر تطبيقات تتبّع لاستهلاك المياه، وتقنيات لإمداد أجهزة إنترنت الأشياء بالطاقة لاسلكيًا إضافةً إلى أجهزة مدعومة بتقنيات إنترنت الأشياء مثل أقفال الأبواب وحساسات الحرارة والثلاجات الصغيرة وأزرار الإنارة.

وأشار بعض فلاسفة العلم والمهتمين بالعلاقة بين التعليم والتطوّر التقني إلى أن المجتمعات باتت تجهز طلابها لوظائف ومههات لم تظهر بعد، كما أنهم يعدونهم لاستخدام تقنيات لم تنتج بعد، وتدربهم علن حل مشاكل لم تواجهها حتى الآن، ويتوقع هؤلاء أيضاً أن يعمل كثيرون من خريجي الجحامعات في مؤسّسات افتراضيّة لا ترتبط بموقع أو مقر معين. ويتناسب ذلك النوع من المؤسّسات مع أعحال كثيرة كالاستشارات والمحاماة والصحافة والنشر والصحة النفسيّة والعمل الخيري وغيرها من الأعمال التي تتطلب وجود فريق عمل منسّق، كما ستكون بيئة الأعمال موزّعة وعالميّة. يضاف إلى ن.

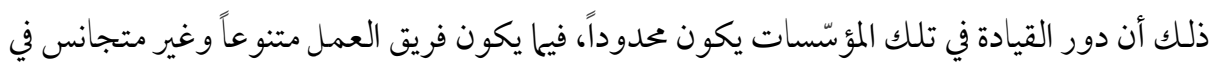
الثقافة واللغة والقيم والأعراف والقوانين. وفي هذا الاطار بدأت الجامعات المصرية وبتوجيه من المجلس الاعلن للجامعات باقتراح انشاء اقسام للذكاء الاصطناعي وانترنت الاشياء، وفقاً لاهتحام القيادة السياسية المصرية بوضع الاستراتيجية المصرية للذكاء الاصطناعي، وضرورة إعداد الطالب المصري لدراسة الذكاء الاصطناعي وتنمية مهار اته العلمية، حيث تمت الموافقة من قبل المجلس الاعلئ للجامعات في جلسته بتاريخ ع ا مارس 9 1 • ب علئ اقتراح تغيير مسمى كلية الحاسبات والمعلومات جامعة القاهرة المى كلية الحاسبات والذكاء الاصطناعي لتضم قسم يتعلق بالذكاء الاصطناعي بها، وكذلك علن اقتراح جامعتي المنوفية وكفر الشيخ بإنشاء كلية للذكاء الاصطناعي بها، تضم قسما عن انترنت الاشياء. كما وافق بجلس خدمة المجتمع وتنمية البيئة بجامعة الإسكندرية، علن مقترح كلية الهندسة باستخدام تكنولوجيا إنترنت الأشياء داخل الجامعة بهدف تحويلها إلى جامعة ذكية. وقال الدكتور 
هشام جابر، نائب رئيس جامعة الإسكندرية لشئون التعليم والطلاب، إن المقترح يعمل من خلال

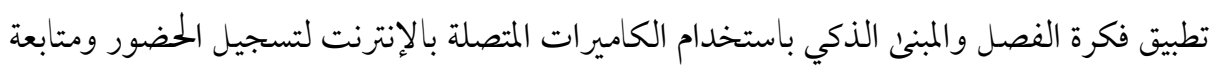

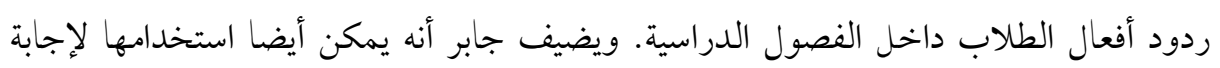

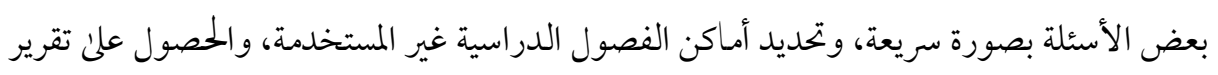
عن مدئ استغلال الأماكن والمعامل بالجمامعة.

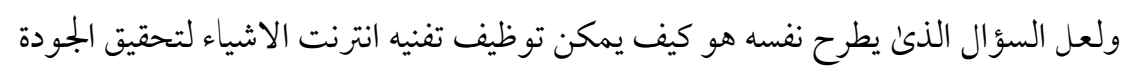

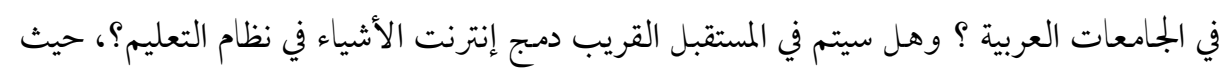

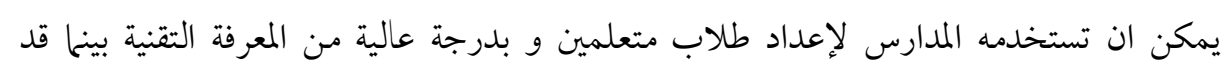

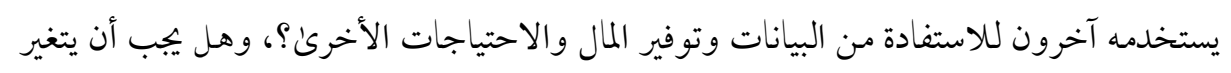

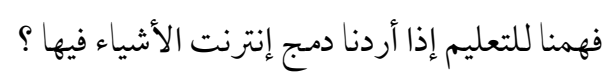

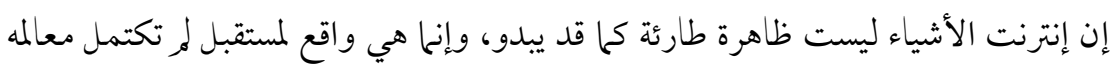

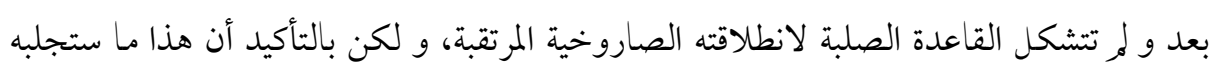

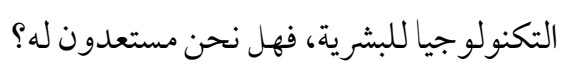

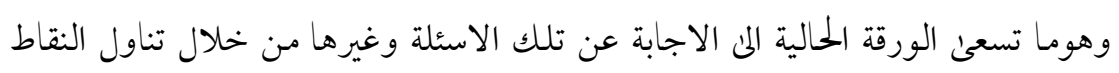
التالية:

$$
\text { - - - المقصود بإنترنت الاشياء وخصائصه وبجالات تطبيقه }
$$

- - - مالمبرات التي تدعو المن ضرورة الاستفادة من تقنية انترنت الاشياء في المجال التعليمي

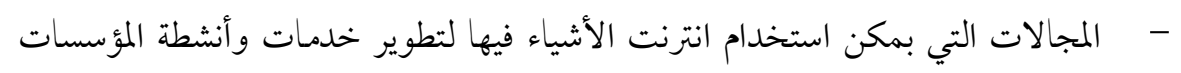
التعليمية. - التحديات التي تواجه استخدام انترنت الاشياء في بجال التعليم.. 


\section{أولا: المقصود بإنترنت الاشياء وخصائصه وبجالات تطبيقه}

ترجع نشأة انترنت الاشياء و أول ظهور لهذا المصطلح المي كيفين آشتون Kevin Ashton الذي اقترح عبارة إنترنت الأشياء "Internet of Things" لأوّل مرةٍ عام 1999 كعنو ان لعرضٍ توضيحيِ قدّمه في مكان عمله بروكتر أند غامبل .Proctor \& Gamble خلال عمله في ذلك المكان خطرت لآشتون فكرةٌ بأن يضع إشارات التعقب الراديوية مFID tag على أحمر الشفاه وتوصليها مع مستقبلٍ لاسلكيٍّ ليتمكّن من رصد المبيعات وقائمة الجرد وإعطاء إشارةٍ عند الحاجة إلى مخزوٍٍ إضافيّّ، حيث افترض بأن مثل هذه البيانات المجمعة ستساعد علن حلّ العديد من المشاكل في العالم الحقيقي. ثم استُخدم المصطلح في أطروحات نيل جيرشينفيلد الذي كان يتحدث عن أفكار مماثلة من معمل الإعلام في معهد ماساشوستس للتقنية في كتابه" عندما تبدأ الأشياء في التفكير"،

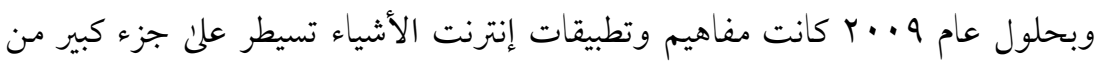
البحوث والدراسات الأكاديمية، والتطبيقات التي تحاول الاستفادة منها، أصبح عدد الأشياء المتصلة بشبكة الإنترنت أكبر من عدد الأشخاص المتصلين بالشبكة نفسها. تضمّن إنترنت الأشياء (IoT) أو كما يُشار إليه بإنترنت كلّ شيء

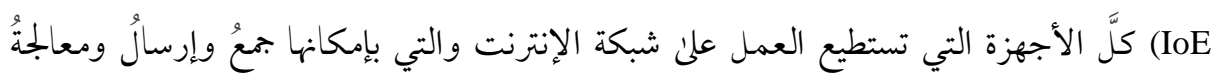
البيانات التي تلتقطها من بيئتها المحيطة مستخدمةً لذلك حساساتٍ مضمنة ومعالجاتٍ بالإضافة إلى وسائط اتصالِ، وتُدعى غالبًا بالأجهزة المتصلة أو الذكية لأنها تستطيع التواصل مع الأجهزة الأخرىن المرتبطة بها بعمليةٍ تُعرف باتصال آلةٍ بآلةٍةِ (machine-to-machine (M2) ، والتفاعل مع المعلومات

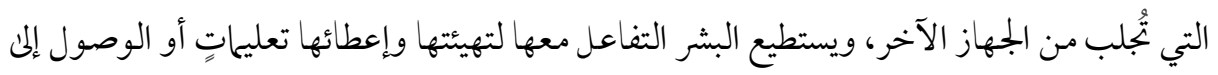
البيانات، ولكنها تقوم بمعظم علمها دون تدخلِ بشريٍّ، أصبح وجود مثل هذه الأجهزة مكنًا بفضل جميع عناصر الهاتف الذكي الصغيرة المتوفرة بكثرةٍ هذه الأيام بالإضافة إلى كون الاتصال الدائم بالإنترنت هو الحالةُ الافتراضية لشبكاتنا المنزلية أو شبكات العمل. 
وغالبا ما تنتج هذه الأجهزة المتصلة تزاحمًا كبيرًا في شبكة الإنترنت، متضمنًا كمياتٍ كبيرةٍ من أنسا

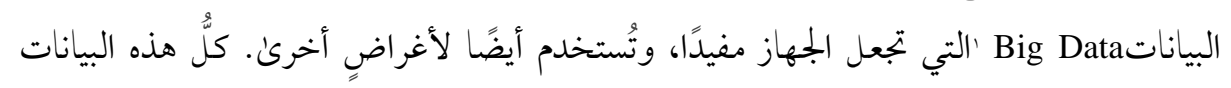

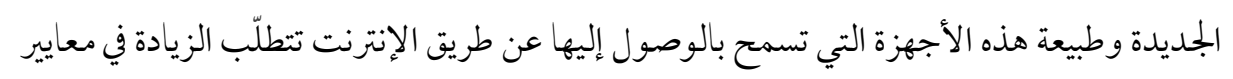
الخصوصية والأمان.

والواقع ان انترنت الاشياء مصطلح تقني يشير إلن الجيل الجديد المتطور والمتنامي بشكل

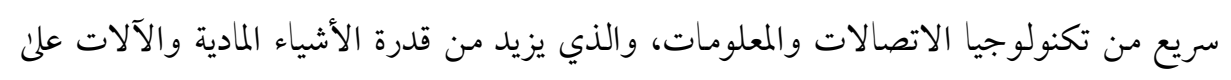

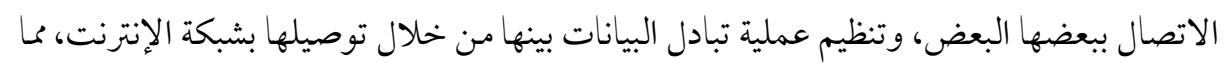

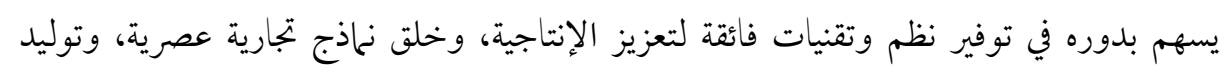

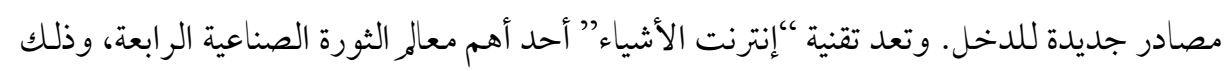

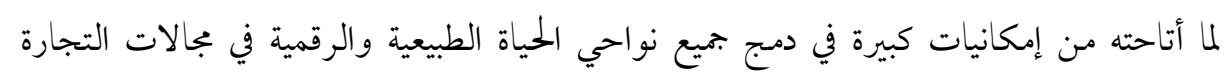

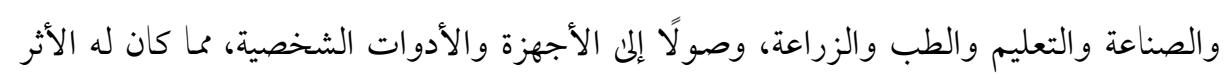

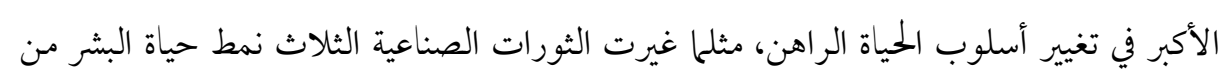
قبل.

وقد عرّف الاتحاد الدولي للاتصالات ITU) (International Telecommunication

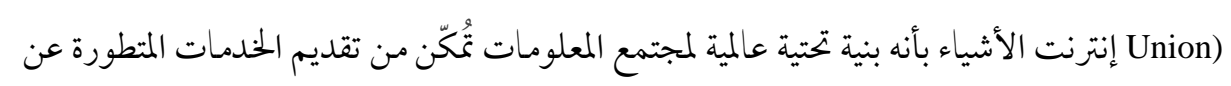

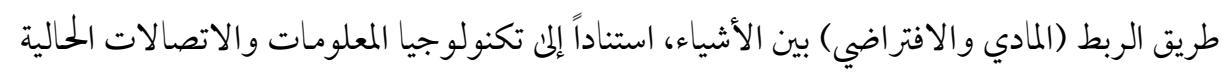
والمتطورة القبابلة للتشغيل البيني.

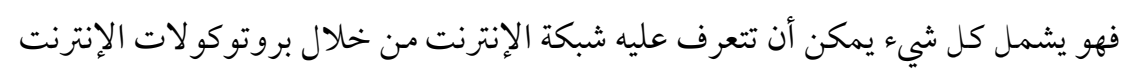

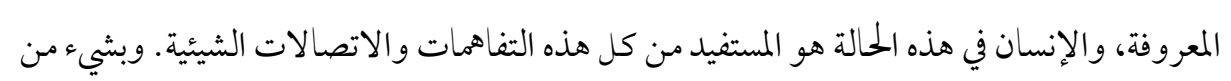

- البيانات الضخمة : مصطلح متطور يصف كمية ضخمة جداً من البيانات المُهيكلة وغير المُهيكلة، يمكن

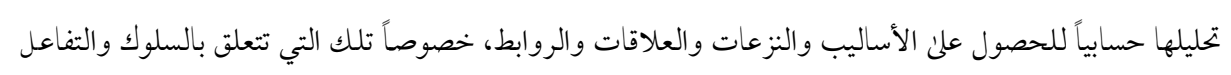

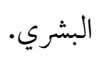


الخيال العلمي، يصبح الإنسان نفسه (شيئً) إذا مـا ألُلصق به أو بمحيطه عنوان إنترنت معين، كأن يُلصق به نظارة أو ساعة أو سوار أو ملابس إلكترونية أو أجهزة أو معدّات طبية علئ أو داخل جسمه.

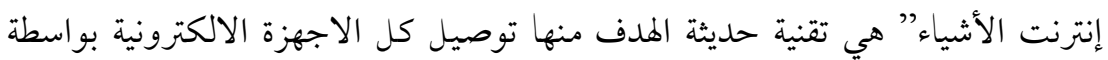
الانترنت بحيث تكون قابلة علن التواصل في ما بينها عن طريق بروتوكو لات خاصة وايضا التواصل

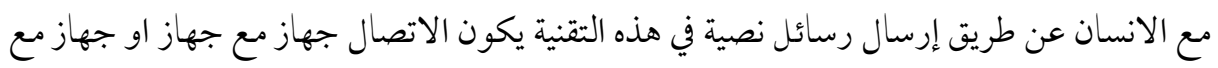

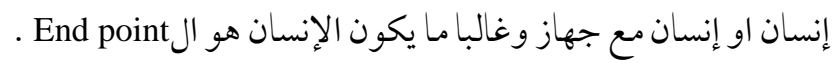
ان أنظمة آل IoT عبارة عن شبكة متنامية بشكل رهيب من الأشياء المادية المتّصلة بالإنترنت

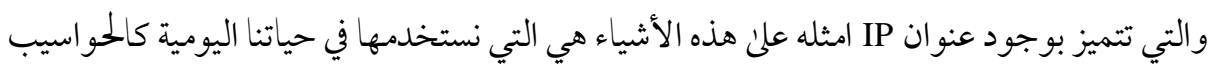
المحمولة والهواتف الذكية والأجهزة اللوحية وكذلك تتمثّل هذه الأشياء بأجهزة الإنذار المنزلية،

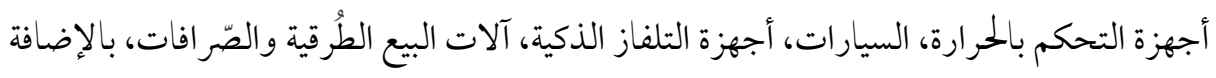

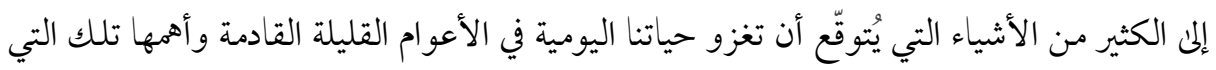
بات بإمكاننا ارتداؤها كالساعات والنظارات. ويوضح الرسم البياني التالي حجم الزيادة المتوقعة في عدد الاشياء المتصلة بالإنترنت

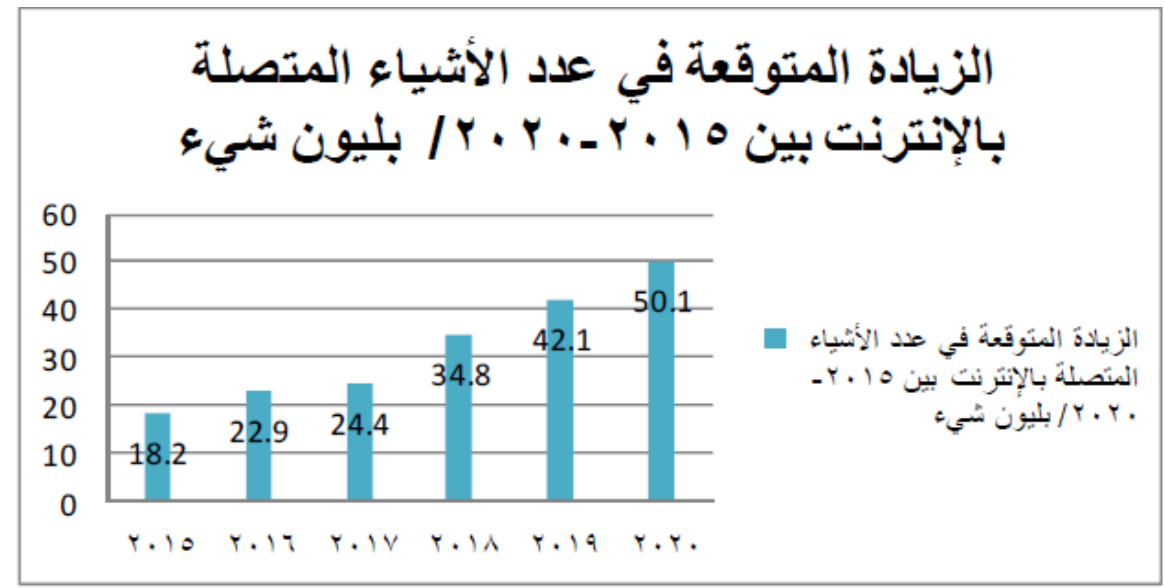

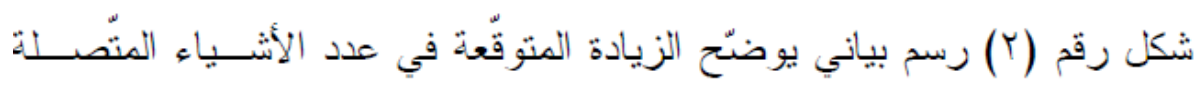
بالإنترنت خلا السنوات الخمسة القادمة.

http://dx.doi.org/10.29009/ijres.2.3.1 
وفي ضوء ذلك تعرف انترنت الاشياء علن انها عبارة عن شبكة كبيرة من الأنظمة المختلفة مثل أجهزة الكمبيوتر والهواتف النقالة وأنظمة السيارات وأنظمة المصاعد وغيرها من الانظمة المختلفة الموجودة في حياتنا اليومية، حيث يتم دمبج هذه الأنظمة بسهولة وسلاسة يبعضها البعض من خلال شبكة الإنترنت لتتمكن من تبادل المعلومات بينها. يمثل إنترنت الأشياء نقلة ثورية في مفهوم الإنترنت والاتصالات، حيث تصبح الآلات المتصلة بالإنترنت هي مصدر البيانات بدلاً من أن يقوم

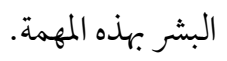

اما عن خصائص انترنت الاشياء: فانه في ضوء التعريفات السابق عرضها تتحدد خصائص

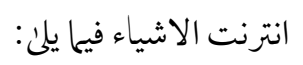

1- قلة دور العامل البشرى : فأي شيء يتطلب التفاعل البشري لا يعتبر من نظام انترنت الأشياء.IoT والتدخل البشري هنا يجب أن يكون علن الأغلب لتشغيل النظام أو اطفاءه

فقط.

انترنت الأشياء هو M2M (mechaine to mechaine لا يجب أن نقول ان التحكم بالإنارة عن طريق البلوتوث أو الواي فأي أو أي شيء آخر يتدخل البشر في التحكم به هو نظامIoT ـ، الأجهزة في انترنت الأشياء هي التي ترسل وتستقبل المعلومات وتعالجها تلقائيا

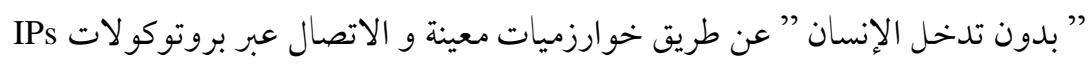

$$
\text { وتقدم النتيجة للبشر. }
$$

ץ- إن إنترنت الأشياء ليست مجرد شبكة من أجهزة الحاسوب فحسب، بل هي في أبسط

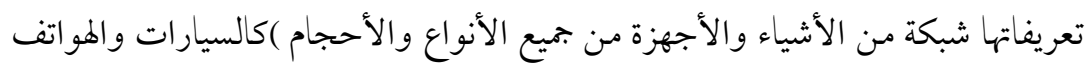

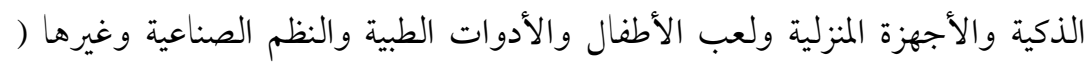
المتصلة مع بعضها علن نحو تفاعلي، بحيث يتم. )تبادل المعلومات فيها بينها في كل وقت

$$
\text { مثلما يوضح الشكل التالي }
$$




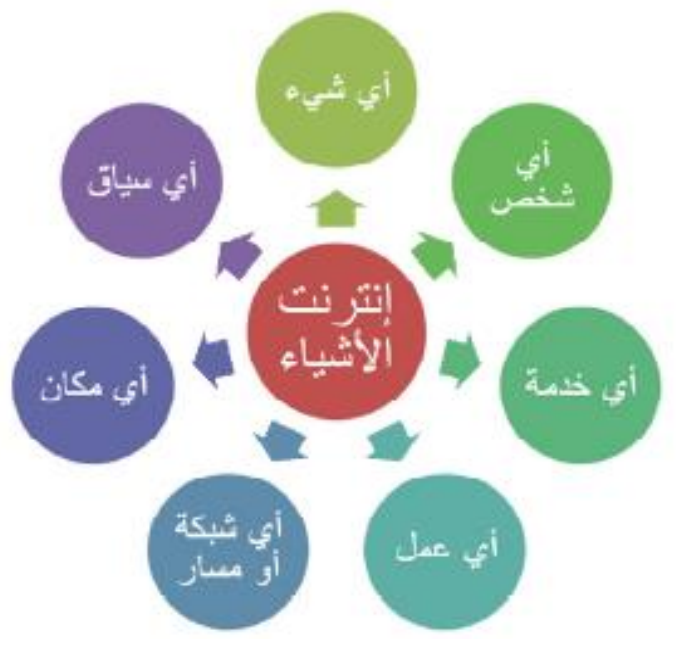

r- انترنت الاشياء هو مفهوم متطور لشبكة الإنترنت بحيث تمتلك كل الاشياء في حياتنا قابلية الاتصال بالأنترنت أو ببعضها البعض لإرسال واستقبال البيانات لأداء وظائف محددة من

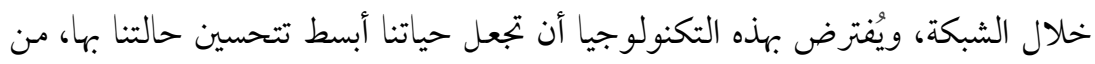
خلال ربط العديد من الأشياء المتنوعة والمتعددة عبر وسائط استشعار، والتحكم بها من

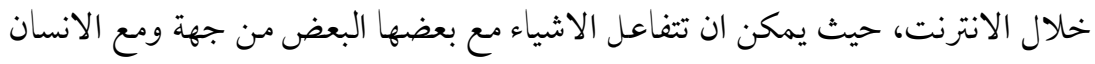

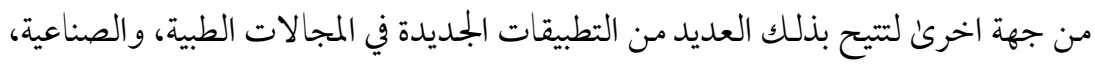

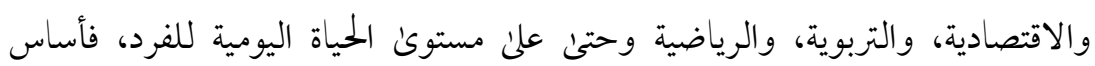

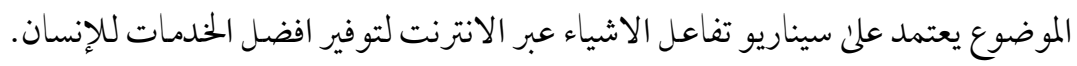

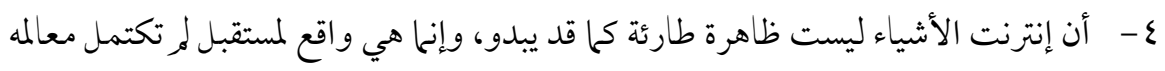

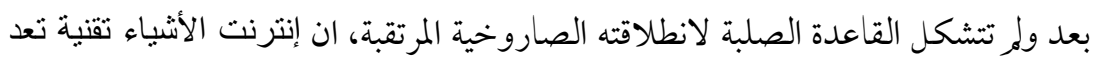

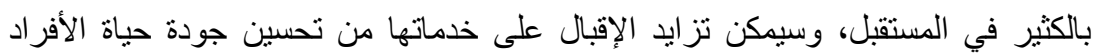

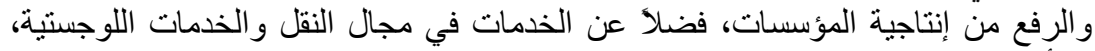
و الأمن و المر افق و التعليم والرعاية الصحية، و غير ها من المجالات 
0- ت تكون إنترنت الأشياء من ثلاثة عناصر رئيسية: هي: الأشياء: المقصود بها هنا كل شيء

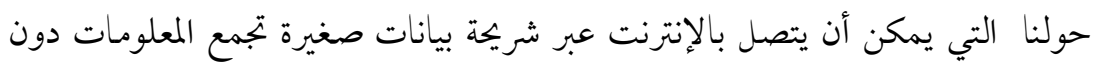

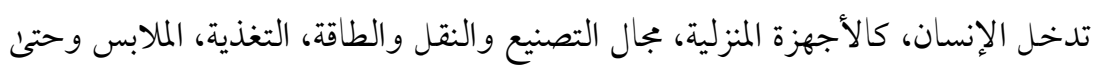
جسم الإنسان والحيوان، وغيرها، وشبكات الاتصالات التي تربط بينها، وكذلك نظم الإنس

$$
\text { الحوسبة التي تعالج البيانات التي ترسلها الأشياء وتستقبلها. }
$$

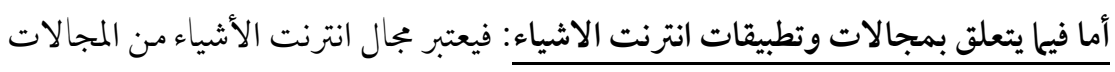

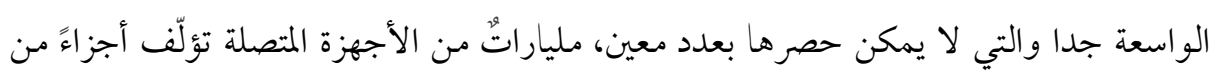

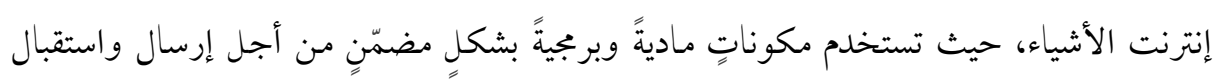

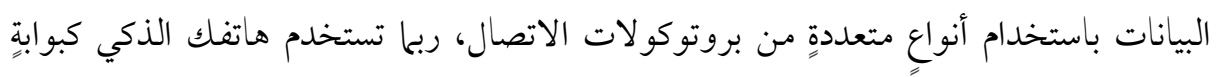

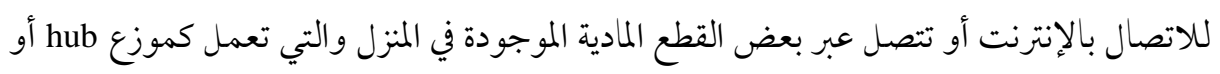

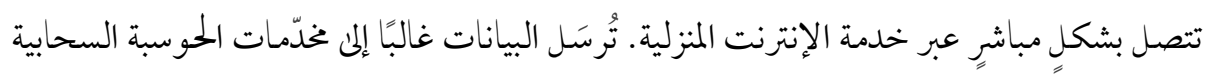

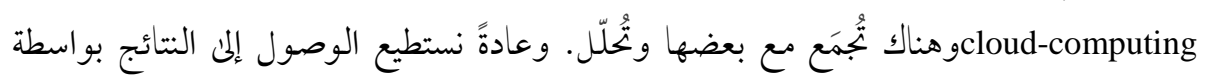

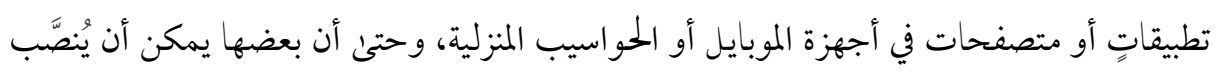
لتحديث حالاتك علن شبكاتٍ اجتماعيةٍ متنوعةٍ.

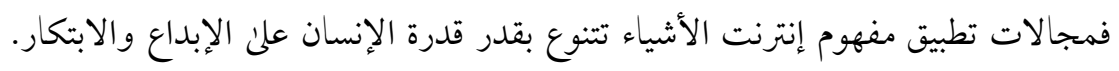

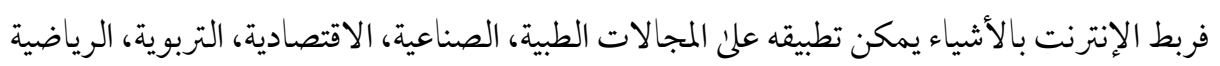

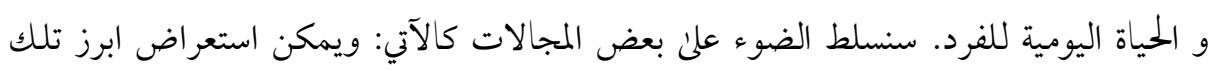

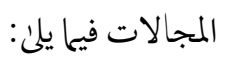


1- المنازل الذكية/ المتصلة Home Automation (Connected/Smart Homes)
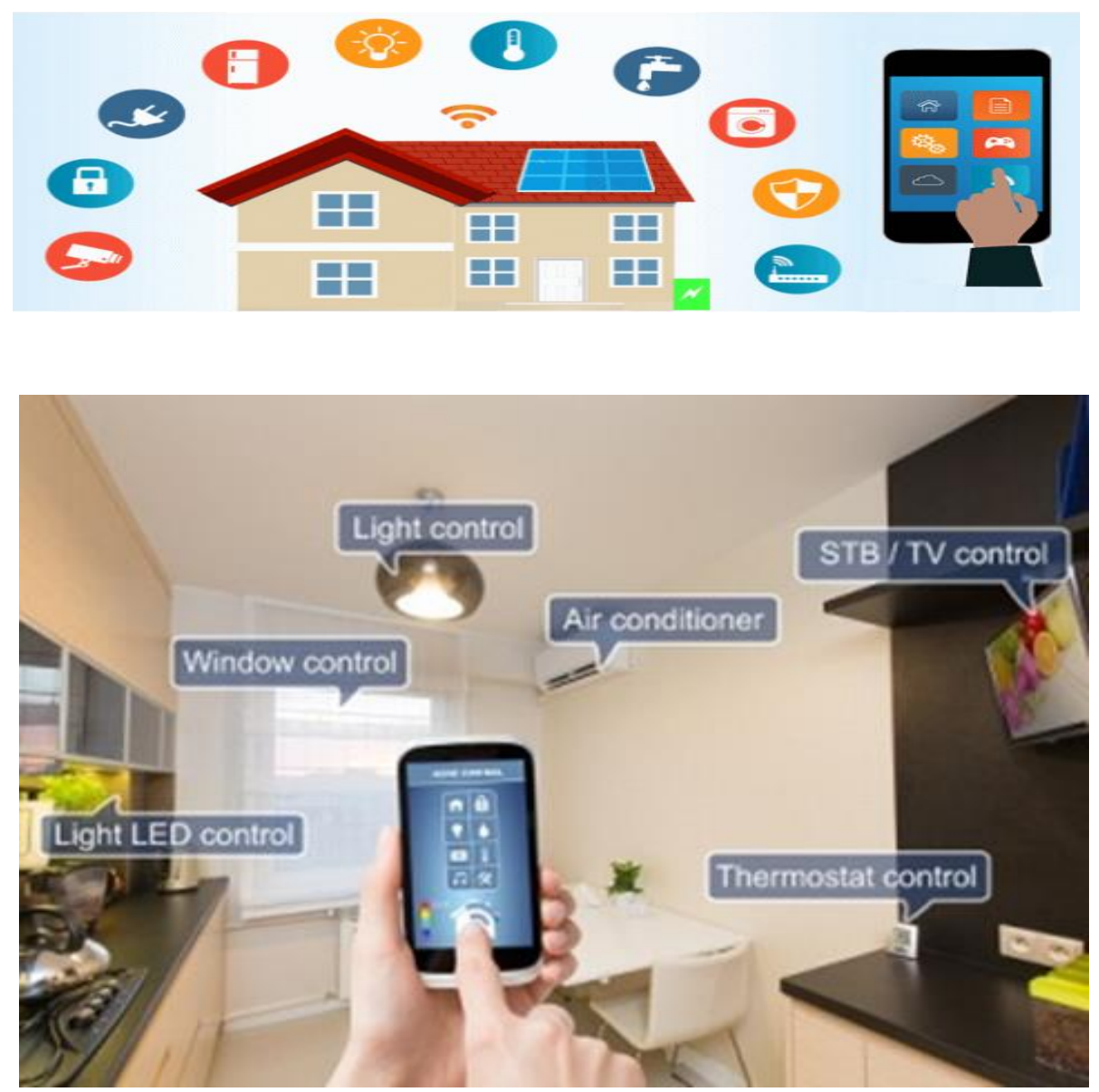

المنزل الذكي هو المنزل الذي يحتوي علن أجهزة لديها القدرة علن التو اصل بعضها مع بعض، ومع بيئتها غير المادية. ويعطي البيت الذكي المالك القدرة علن تخصيص ومراقبة البيئة المنزلية، لزيادة الأمن وإدارة كفاءة الطاقة، وهناك المئات من تقنيات إنترنت الأشياء المتاحة لرصد وبناء المنازل الذكية من بينها: 
- - - أنظمة الأمان والانذار: اصبحت أنظمة الأمان الموجودة علن مداخل العمارات والمنازل

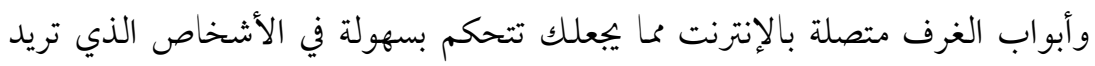

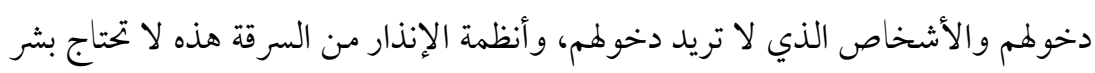

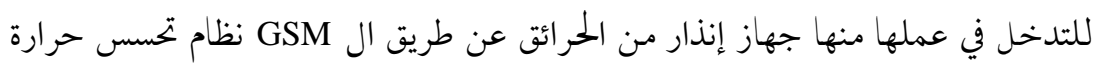

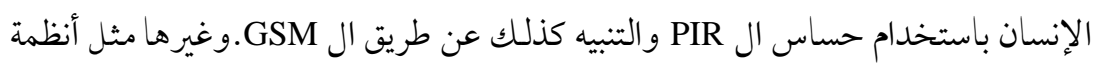

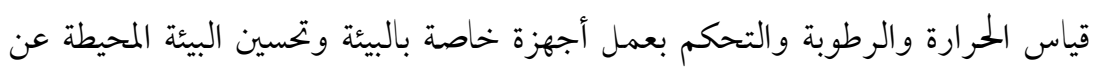
طريق معالجة البيانات وغيرها من تطبيقات أنظمة الإنذار المنزلية المختلفة والسيارات الحديثة و أجهزة التلفاز الذكية و الصرافات النقدية. - الغسالات الكهربائية: باتت الغسالات متصلة بالإنترنت بشكل سهل مما يساعد ربة البيت

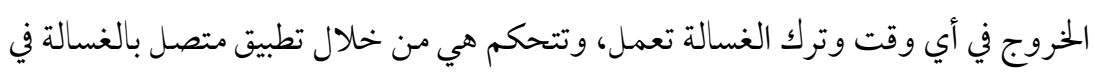

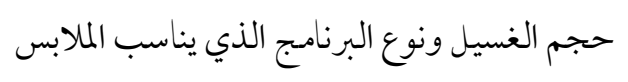

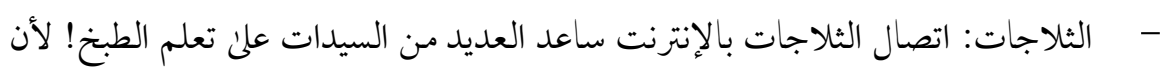

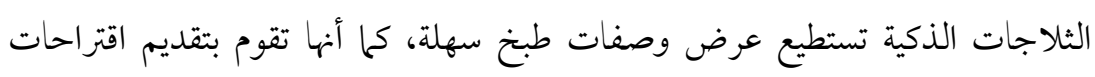

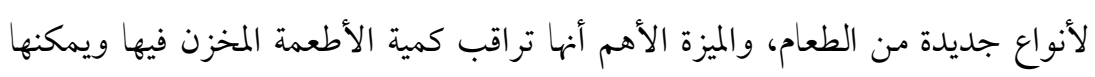

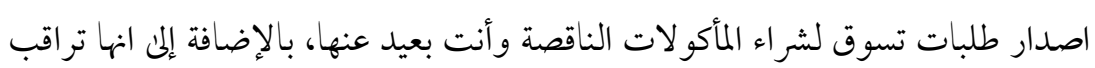

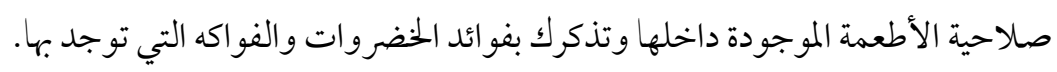

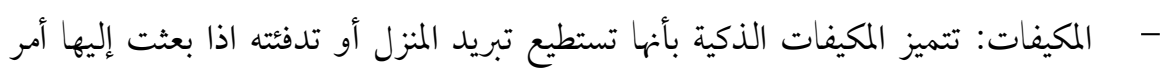

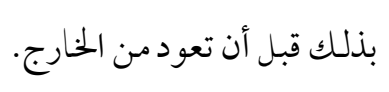

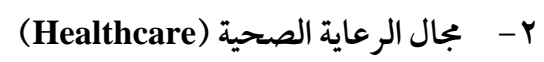

تهدف تقنيات إنترنت الأشياء في مجال الرعاية الصحية إلى تمكين الناس من عيش حياة صحية

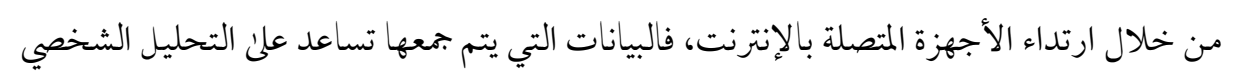


لصحة الفرد، وتوفير استراتيجيات مصممة خصيصاً لمكافحة المرض وربها تساعد علئ تقديم رعاية عاجلة في الحالات الطارئة. وتوجد العديد من التطبيقات لإنترنت الأشياء في المجال الطبي، من ابرزها، نقل بيانات المريض من المنزل المى العيادة او المستشفى، تكامل الأجهزة الطبية وإمكانيات تبادل البيانات فيما بينها، تحسين طرق تقديم الأطباء للرعاية، تعزيز مشاركة المرضى وتفاعلهم مع الأطباء. إدارة أجهزة متعددة متصلة، إمكانية تحويل بيانات انترنت الأشياء المى إجراءات من قبل الأطباء، تشخيص أكثر دقة

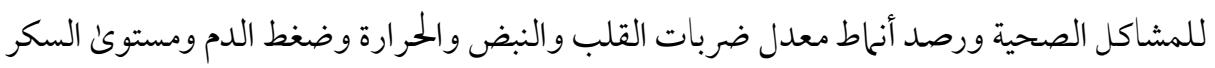
بالجسم والجهاز الهضمي، إمكانية إرسال المعلومات إلى الطبيب لتحليلها واتخاذ الإجراء الطبي المناسب، الأجهزة المتصلة تأخذ البيانات الحيوية بالجسم علنم مدار اليوم وتنقل لاسلكيا إلى أجهزة

$$
\text { الطبيب مثل الحاسوب و الهاتف الذكي، وغيرها. }
$$

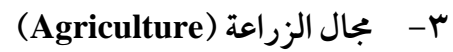

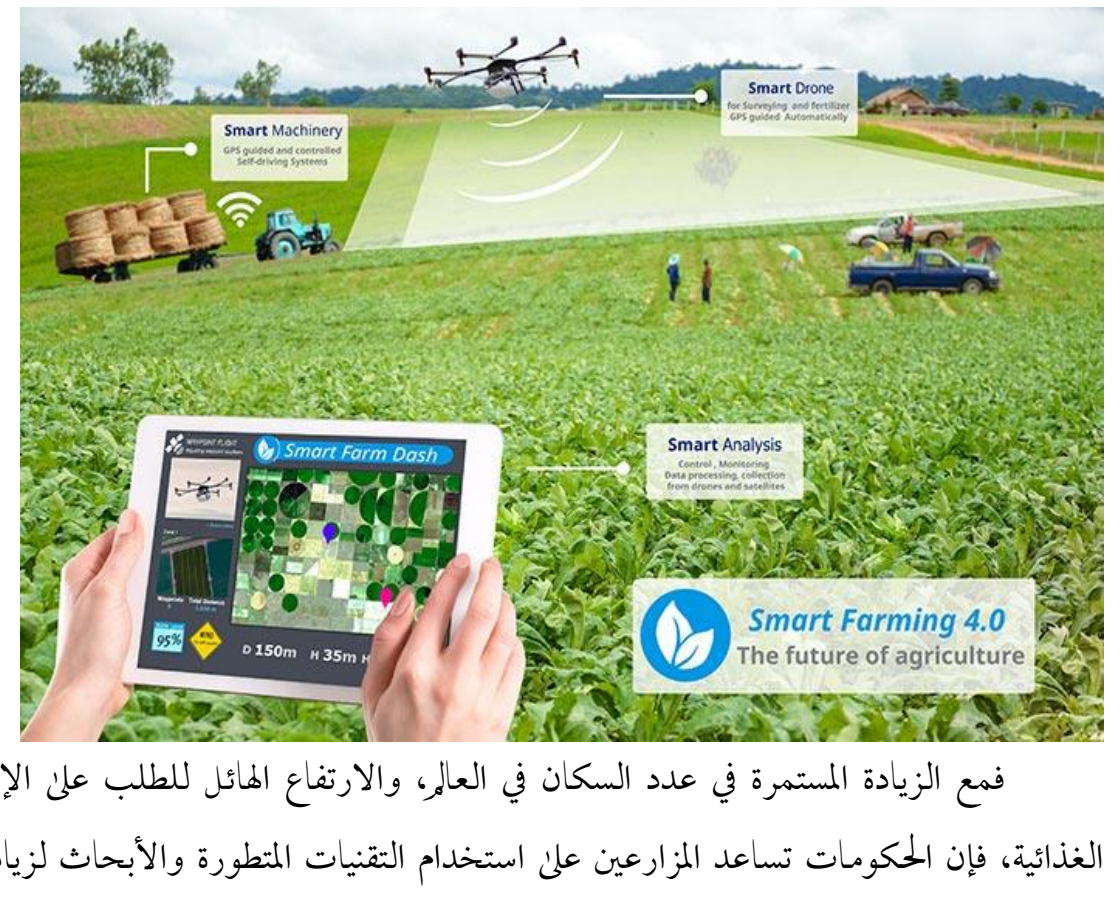

http://dx.doi.org/10.29009/ijres.2.3.1 
الغذاء، أو محاربة الحشرات الضارة، أو تحسين جودة الغذاء، والزراعة الذكية (Smart Farming) هي واحدة من أسرع الحقول نمواً في مجال إنترنت الأشياء، كما ان تطوير أنظمة الزراعة والفلاحة فهو يساعد الفلاحين علن فحص صحة الأبقار والماشية والدواجن، ويمكنه التعرف بسهولة على أي مراض يحملوها، كما يساعد الفلاحين علن معرفة أي نوع من الممكن أن يزرعه في هذا الوقت من بن بلن السنة.

ع - السيارات ووسائل النقل (Transportation /Automotive)

السيارة المتصلة بإنترنت الاشياء، هي السيارة القادرة على تحسين طريقة اشتغالها وتوفير الصيانة، فضلاً عن توفير راحة الركاب الذين يستخدمون أجهزة الاستشعار وشبكة الإنترنت علن فئن متنها، فقد ساعد الانترنت علن التمتع بقيادة السيارات فهو قام بتوفير متع متعددة منها خرائط الكترونية تعرفك علن المسار الذي تريده ويبعدك عن الطرق المزدمة بجانب ميزة تشغيل لموسيقي من خلال الانترنت، عمل انترنت الاشياء علن اعطاء السيارات تقنية مميزة وهي خاصيات التبريد و التدفئة الأوتوماتيكية مع عرض حالة الطقس للأماكن التي ينوي قائد السيارة اذهاب إليها، ونظام

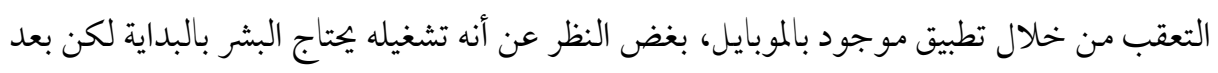
ذلك سوف يكون الاتصال تلقائي من حيث إرسال واستقبال الإشارة عن طريق GPS مع الأقمار الصناعية لتحديد المسار المناسب للسائق وكل ما عليه هو مشاهدة الخريطة ويبقى تحليل ومعالجة إلجة البيانات للحصول علن هذه النتائج بين آل GPS والقمر الصناعي وليس للبشر دخل في ذلك غير المشاهدة و الاطلاع علن الخارطة.

ه - الملابس الذكية أو الملبوسات الإلكترونية (Wearable)

يعني هذا المصطلح كل التقنيات الذكية القابلة للارتداء، كالساعات اليدوية والأساور والنظارات التي تتنوع وظائفها بين الترفيه والرياضة والصحة، وهي واحدة من أهم الاتجاهات في إنترنت الأشياء حالياً، ويتنافس عدد من الشركات العالمية كشركة آبل (Apple)، جوجل (Google) أو سامسونج (Samsung) وآخرين في مجال تصنيع هذه الأجهزة. يتم تثبيت الملبوسات الإلكترونية 
مع أجهزة استشعار وبرجيات، تقوم بجمع البيانات والمعلومات عن المستخدمين، وبعد ذلك تتم

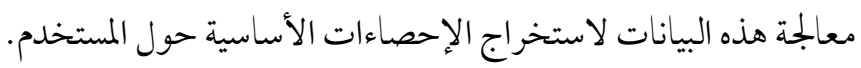

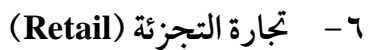

إمكانات إنترنت الأشياء في قطاع التجارة بالتجزئة هائلة. تخيل أن تكون أجهزتك المناك المنزلية

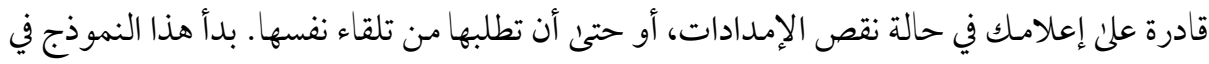

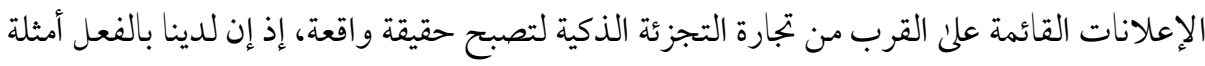
عن تطبيقات إنترنت الأشياء كجزء من سلاسل التوريد الذكية، وتطبيقات لتتبع البضائع، وتبادل المعلومات بشكل فوري حول المخزون بين الموردين وتجار التجزئة إضافة إلى التسليم الآلي.

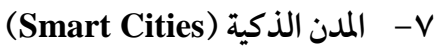

المراقبة الذكية، النقل الآلي الذكي، ونظم إدارة الطاقة والرصد البيئي الذكي، كلها أمثلة علني

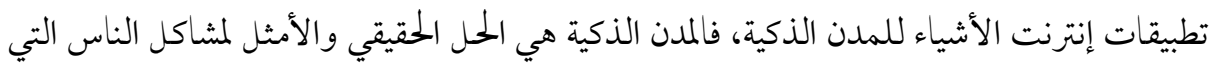
عادة ما تواجهمم بسبب الانفجار السكاني والثلوث، وضعف البنية التحتية والنتص في إمدادات

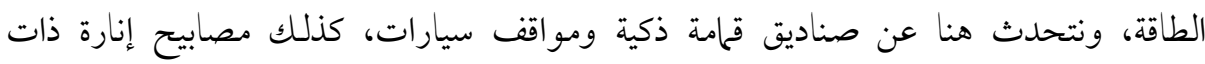
مستشعر ات، تجعلها أكثر خدمة للمو اطن وأكثر ترشيداً للطاقة. تطوير اداء الموظفين ومتابعة اعلهم وتسهيل اداء الكثير من تلك الاعمال حيث أصبحت الشركات لا تتخلي ان الانترنت في كل شيء تستخدمه.

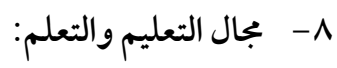
إن المجالات التي يمكن أن تقود فيها إنترنت الأشياء العملية التعليمية كثيرة ومتنوعة ويشير Mikkie Mills النى ان تطبيقات انترنت الاشياء Internet of Things (IoT) في التعليم ستكون مفيدة له، لاسيا لنظام التعليم المتطور باستمرار. 
- ساعد الطلاب علن التعلم بصورة جيدة وميسرة، فمع إنترنت الأشياء، يمكنكهم استخدام

$$
\text { هو اتفهم الذكية للحصول علن مزيد من التوضيح حول مـا تعلموه. }
$$

- قبل أن تصبح الشهادات عبر الإنترنت مستقبل التعليم، كانت محدودة فيما يتعلق بلاذا وأين

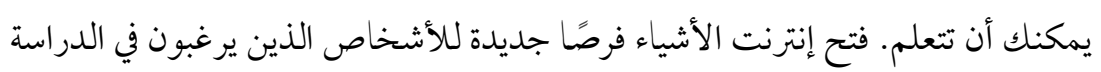

$$
\text { من أي مكان وفي أي وقت. }
$$

- - متكن إنترنت الأشياء المتعلمين من الانفتاح على طرح الأسئلة لأنها فردية. هذا يعني أنه يزيد

$$
\text { من مشاركة الطلاب. }
$$

- - يسمح إنترنت الأشياء للطلاب بتتبع تقدم التعلم وتقييم أدائهم ونتائجهم.

\section{بالنسبة للمعلمين: - n}

- - متنحك المعلم إنترنت الأشياء امكانية الوصول إلى عدد من المواد التعليمية عالية الجمودة. يمكنك استخدام الأدوات المتوفرة لإنشاء محتون خاص لطلابك ثم إرساله إليهم مباشرةً

$$
\text { علن الأجهزة اللوحية والهو اتف الذكية الخاصة بهم. }
$$

IoT لأولئك الذين لا يمضرون الفصل، يمكنك متابعتهم بشكل فردي من خلال النظام عبر الإنترنت، ومعرفة أسبابهم دون جعلهم يشعرون بعدم الارتياح.

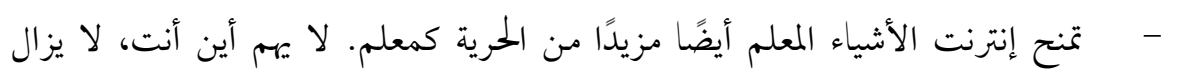
بإمكانك مر اقبة تقدم طلابك و التواصل معهم من خلال النظام.

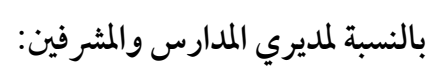

- - ميسمح انترنت الاشياء للمدير بمراقبة الأروقة والفصول الدراسية أو أي غرفة أخرىن

$$
\text { داخل المدرسة. }
$$


- يتيح إنترنت الأشياء للمدير والمشرف الحصول علن المراقبة بالفيديو للمؤسسة من خلال هاتفك الذكي أو جهازك اللوحي أو الكمبيوتر المحمول أو سطح المكتب. يساعد IoT المدير أيضًا علن مر اقبة نظام التهوية بالمدرسة من خلال جهازك الإلكتروني. وبهذه الطريقة، تتأكد من رعاية الطلاب والموظفين دائمًا.

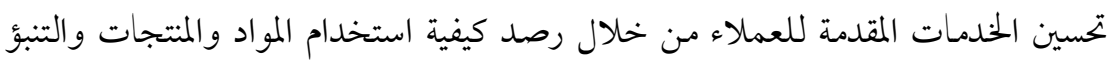
الدقيق بمواعيد صيانتها، وتقليل تعرض للسلع الاستهلاكية إلى الملوثات والعوامل البيئية التي تؤثر

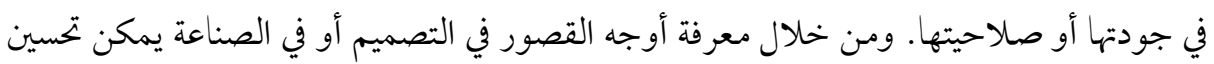

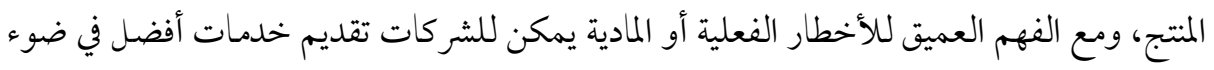
البيانات والمعلومات الموثوقة التي جمعتها بفضل تكنولوجيا إنترنت الأشياء. ثانيا: المبررات التي تدعو المى ضرورة الاستفادة من تقنية انترنت الاشياء في المجال التعليمي:

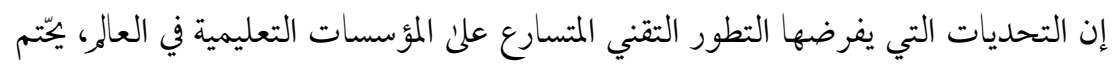
علن هذه المؤسسات مو اكبة هذا التطور علن نحو مستمر، ولاسيا أن كثيرا من محاور التطور والتنمية

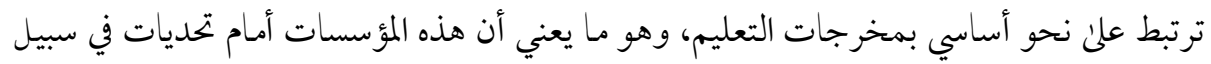
تزويد الخريين بالمهارات المطلوبة لمواكبة هذه التغيرات.

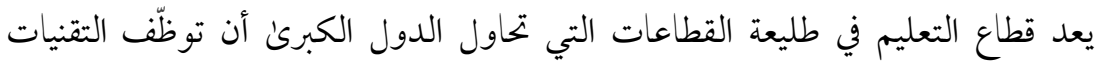
الجديدة في خدمته، إذ يعول علن التعليم من أجل النهوض والتطوير وتبنئ عليه الرؤين المستقبلية.

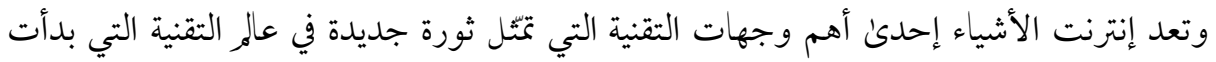
بعض المؤسسات الأكاديمية.

اننا نشهد حاليا الموجة الثالثة في مجال تكنولوجيا التعليم و التي يمكن أن نطلق عليها ”

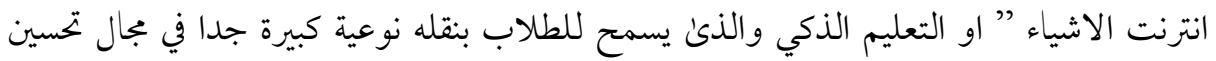

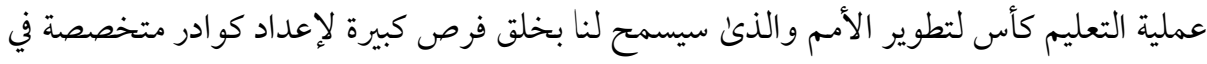

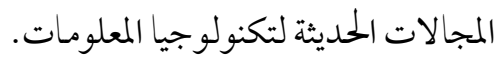


فإنترنت الاشياء يمكن يحسن التعليم نفسه وبساهم في تحسين البيئة المادية والهيكلية، فالمدرسة الذكية لديها مرافق تعمل بسلاسة لتوفر مستوئ أعلى من التعلم الشخصي، فالأجهزة الذكية التي تستخدم في المؤسسة التعليمية باستخدام شبكة واي فأي لإرسال البيانات وتلقي التعليمات مما يساعد

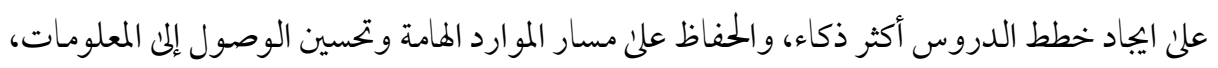
فهي بذلك تساهم في الاتصال السريع بين الطلاب والمعلمين في الفصول الدراسية، وخارجها في أي وقت وأي مكان

ولذلك بدأت العديد من المؤسسات التعليمية بإدراك أهمية إدخال التقنية ودمجها ولا سيا إنترنيت الأشياء في أساليبها التعليمية اليومية، وقريبًا جداً سيتم دمسج إنترنت الأشياء في الأنشطة اليومية للكليات والمدارس، وهناك بعض الأسباب والمبررات للإقدام علئ هذه الخطوة، وتتمثل اهم مبررات الدعوة المى توظيف انترنت الاشياء في التعليم فيما يلن:

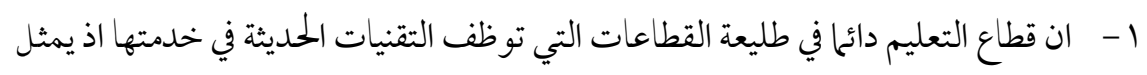
هذا القطاع الركيزة الاساسية التي تبنى عليها توجهات اقتصاد المعرفة والذئ يعد الواجهة الابرز للاقتصاديات الكبرئ في السنوات القادمة. r- ان تكنولوجيا انترنت الاشياء وتطبيقاتها في التعليم اعطت وستعطي الكثير من الميزات والفو ائد لكل من المدرس والطالب والمدرسة، وتساهم في التوضيح العملي الملموس مما يعود علن العملية التعليمية بها يرفع ويعلن جودة التعليم، وتكون خخرجاته ما تحتاجه البلاد

$$
\text { من موارد بشرية مؤهلة. }
$$

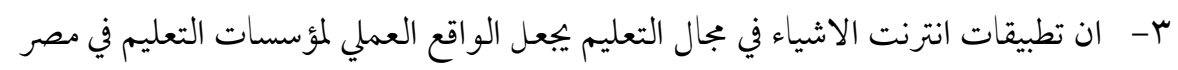
بمختلف مستوياتها مواكبا لكل جديد وحديث في مجالات التكنولوجيا المطبقة عملياً في

$$
\text { التعليم بالعديد من دول العالم. }
$$

ع- يتوقع الخبراء أن تغير إنترنت الأشياء الكيفية التي تعمل بها المدارس والجامعات

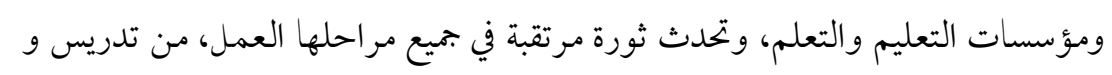


توجيه وتعلم وادارة ومتابعة وتواصل بين كل افراد العملية التعليمية إلى خدمات العملاء الذاتية الإدارة. بل سيمكن ربط جميع الاطر اف بالشبكة الرقمية، مما يعني أنه يمكن أن تتم مر اقبتها عن بُعد حتى بعد الانتهاء من الدراسة والتخرج. 0- إن إنترنت الأشياء هي التقنية المستقبلية التي تترقبها جميع المجالات ومن بينها المؤسسات التعليمية و تتسابق كبرىن المؤسسات لسبر أغوارها وجني ثمارها. وتتسابق عدد من المؤسسات والشركات التكنولوجية لنشر وتعميم إنترنت الأشياء في جميع بجالات حياتنا. لذا يمكننا القول إن إنترنت الأشياء ستصبح قوة عالمية، لكن نرجو ألا تكون مدمرة

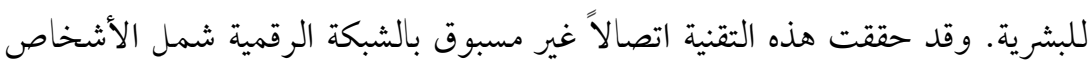
والآلات والأدوات و “"الأشياء” بشكل عام. وتسمح هذه الاتصالات للشركات بمراقبة

$$
\text { معظم العمليات التي تتم حولنا. }
$$

7- أنها تسهم في تخليصنا من المهام البسيطة المتكررة يوميا والتركيز علن الأمور المهمة، وترك الآلات للقيام بالوظائف المتكررة. - - تمكينا تكنولوجيا انترنت الاشياء من درجات عالية من الأتمتة والامتثال للوائح و القوانين والمعايير الصناعية الدولية التي أصبحت أكثر صرامة، من خلال تحسين الحركة داخل المنشأة، وتتبع المو اد الخطرة والمكونات والمنتجات الأخرىن، وكذلك إدارة نقاط الاتصال الحيوي لاسيا في بجال تصنيع الأغذية. ومع ذلك، فإن السعر الحالي لهذه التكنولوجيا لا يساعد كثير اعلن تحسين التكلفة، إضافة إلى التطبيق العملي المشكوك فيه في التطبيقات الفعلية للتكنولوجيا. 1- توّفر هذه التقنية منصة غنية ومرنة للطلاب والمدرسين والإداريين وغيرهم، للاستكشاف والتعّلم والتفاعل مع المنظومة التعليمية في بيئة فائقة الذكاء. 9 - التكنولوجيا المتقدمة تساعد الطلاب على تعلم أشياء جديدة من خلال دعم الأهداف التعليمية، اذ تتيح أدوات للطلاب والمعلمين لمشاركة المستندات عبر الإنترنت وإجراء 
تغييرات في الوقت الفعلي علن الشاشة، ومساعدة المعلمين لتنظيم جميع موارد الطلاب،

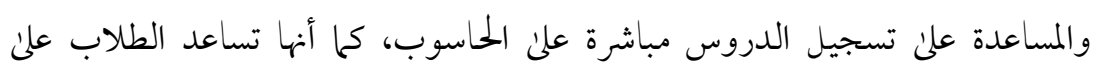

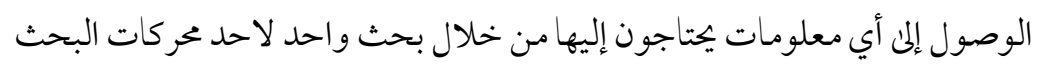

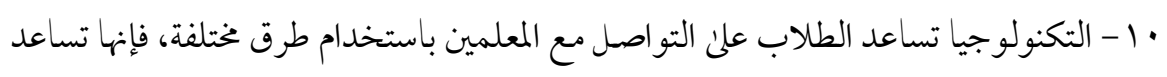

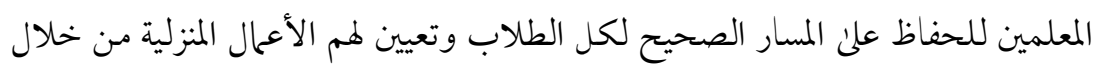

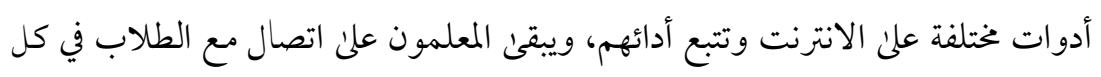

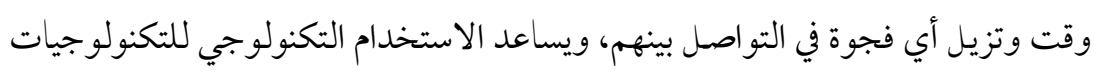
الطلاب على الاضطلاع بأدوار متعلدة ويتحملون مسؤوليتهم الخاصة عن التعلم كما أنها

$$
\text { تمنحهم حرية التعبير والعمل في بيئة حديثة وآمنة }
$$

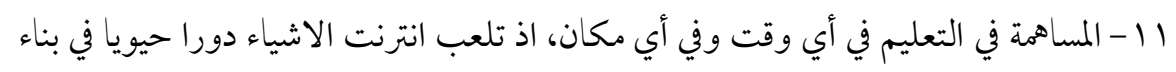

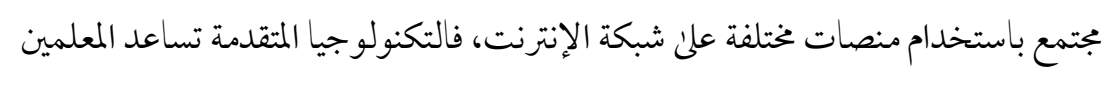

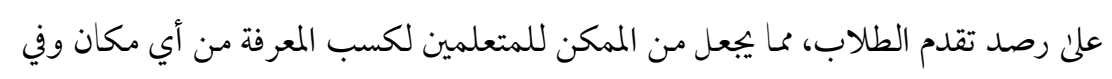

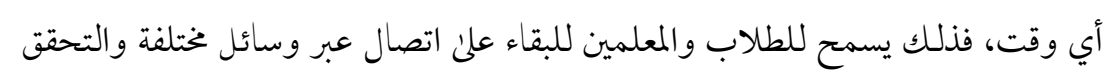

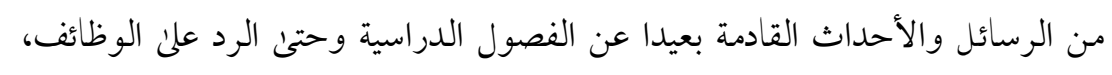

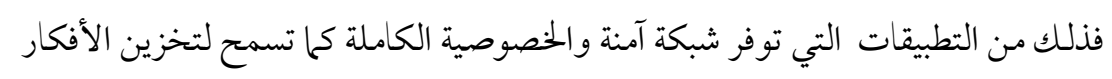
الفريدة وضمان السرية الكاملة. ثالثا: المجالات التي بمكن استخدام انترنت الأشياء فيها لتطوير خدمات وأنشطة المؤسسات التربلة التعليمية. إن المجالات التي يمكن أن تقود فيها إنترنت الأشياء العملية التعليمية كثيرة ومتنوعة

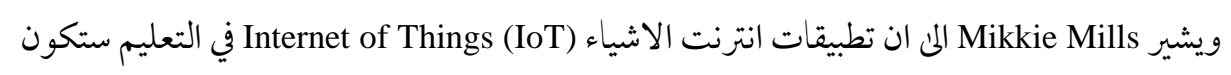
مفيدة له، لا سيا لنظام التعليم المتطور باستمرار. 
كما يؤ كد الخبراء ان إنترنت الأشياء بإمكانه تغيير نظامنا التعليمي بالطرق المذكورة، يمكن أن

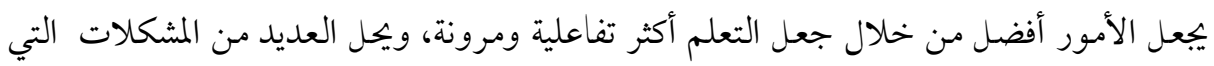
يعانئ منها نظامنا التعليمي فإنترنت الأشياء يمكن أن يساعد في حل المشاكل العديدة المرتبطة المانس بالتدريس التقليدي. علن سبيل المثال، بعض الطلاب خجولون ومتحفظون. يواجه المعلمون مشكلة

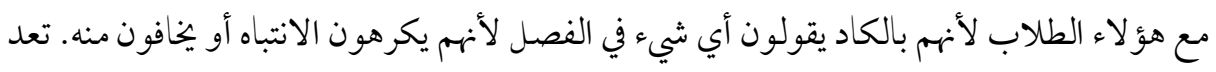

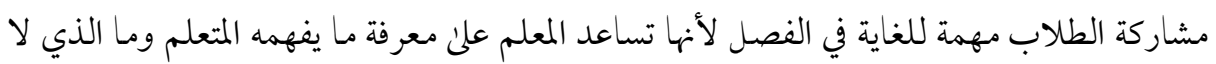

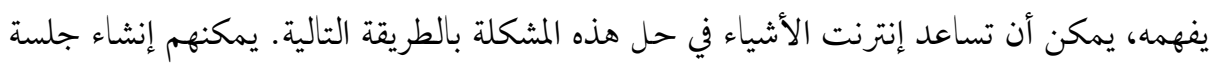

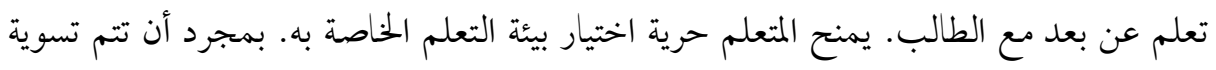

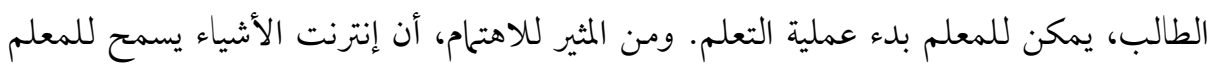

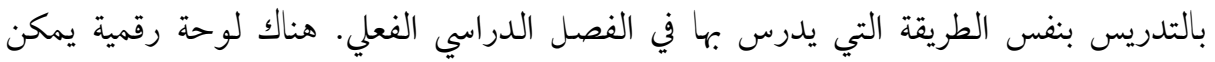

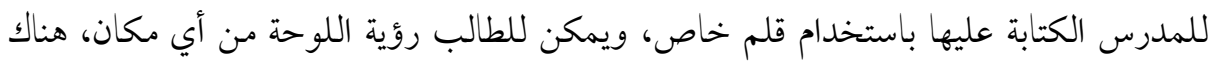

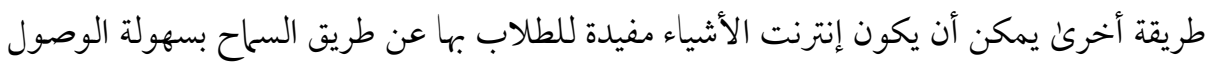

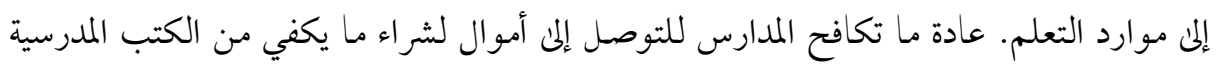

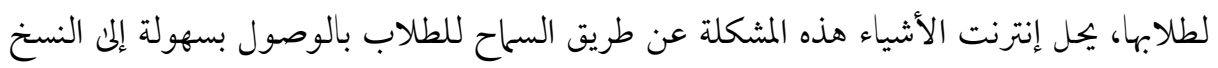

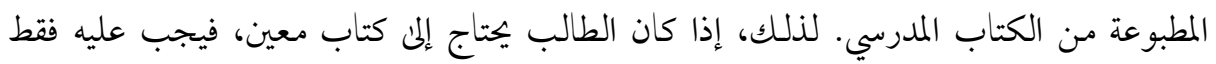

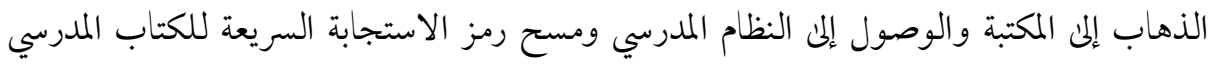

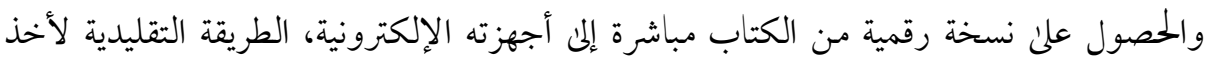

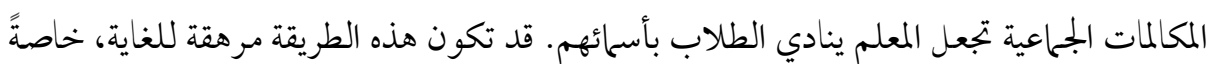

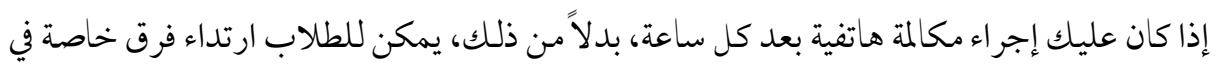

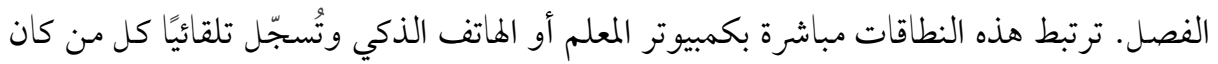

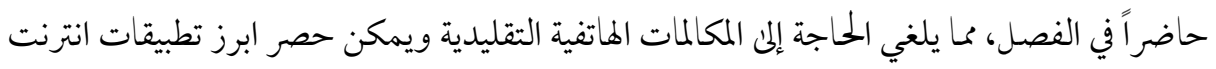
الاشياء في مجال التعليم في التطبيقات التالية:

\section{http://dx.doi.org/10.29009/ijres.2.3.1}




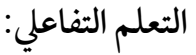

فالتعلم اليوم لا يقتصر المنهج علن مزيج من النصوص والصور ولكن أبعد من ذلك، اذ يتم إقران معظم الكتب المدرسية على مواقع على شبكة الإنترنت التي تشمل مو اد إضافية كأشرطة الفيديو و التقييات والرسوم المتحركة وغيرها من المو اد لدعم التعلم، وهذا يعطي نظرة أوسع للطلاب لتعلم أشياء جديدة مع فهم أفضل والتفاعل مع المعلمين وأصدقائهم، ويساهم المهنيين التربويين بجلب مشاكل العالم الحقيقي المي الفصول الدراسية والسمح للطلاب لإيجاد حلول خاصة بهه.

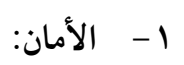

فمع وجود العديد من الطلاب في المؤسسات التعليمية فإن مراقبتهم تعد مهمة صعبة، وعلاوة علئ ذلك فإن الطلاب في المؤسسات التعليمية أكثر عرضة للخطر لذلك يجب استخدام الأمن الذكي مقارنة بالموظفين في أماكن عملهم، فيمكن لإنترنت الأشياء أن يعزز أمن المدارس والكليات

$$
\text { وأي مر اكز تعلم أخرىن بشكل كبير. }
$$

بمساعدة التقنيات مثل تحديد المو اقع ثلاثي الأبعاد يمكن مراقبة الطلاب على مدار الساعة طوال أيام الأسبوع والإبلاغ عن وجودهم في أي وقت بالإضافة إلى توفير خيار أزرار الاستغاثة فبواسطة هذه التقنيات يمكن دق ناقوس الخطر عند الحاجة إلى ذلك. كذلك جانب اخر لتحقيق الامان يتعلق بأقفال وفتح ابو اب الفصول والمدارس لاسلكيا،

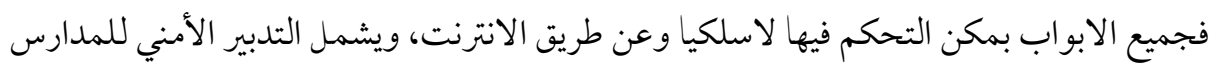

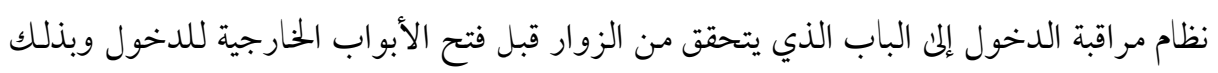
يمكن للمسئول فتح أو قفل الأبواب عن بعد باستخدام الأجهزة النقالة وأيضا تلقي الإخطار عندما يصل شخص ما المى الباب، فذلك ميزة مفيدة لسلطات المدرسة ومساعدتهم علن تجنب أي حوادث، ويمكن أن تبرمج الأبواب للتحقق من حالة قفلها عن بعد عن طريق الجهاز المحمول والقفل تلقائيا في أوقات محددة. ثالث عشر: تطبيق حلول التكنولوجيا المتقدمة في الفصول الدراسية وقطاع التعليم مفيد جدا، مثل التببهات في حالات الطوارئ وتعزيز التواصل الصوتي والساعات اللاسلكية 
والإخطارات السمعية التي توفر للجميع الشعور بالأمن، وبالتالي تعتمد المدرسة إجراءات أمنية خختلفة تساعد علن تأمينها، ويمكن أيضا أن تستخدم وحدة التحكم في الاتصالات لنغخات الطوارئ المختلفة والإعلانات الحية وجداول الجرس والرسائل التعليمية المسجلة مسبقا التي من شأنها توجيه

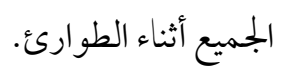

كما يمكن استخدام الكميرا الذكية لمراقبة سلوك الطلاب في الحرم الجامعي. وفي الآونة

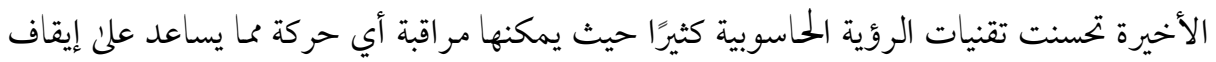

$$
\text { الحو ادث الغير متوقعة من الحدوث. }
$$

يمكن اعتبار التطبيقات التعليمية التي يستفيد منها إنترنت الأشياء أدوات إبداعية قوية وتغير

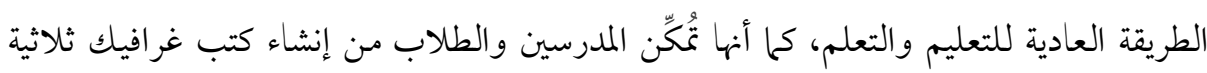

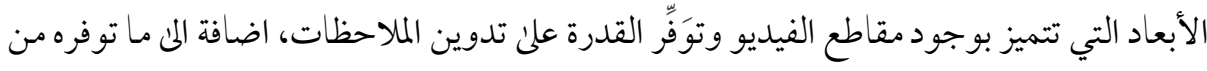
عدد كبير من الألعاب التعليمية. حيث توفر هذه الألعاب العديد من الميزات التي تقدم إمكانيات

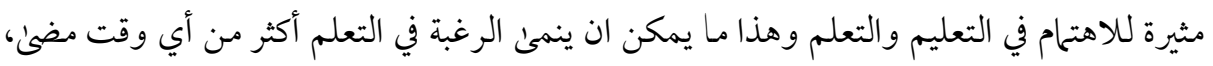

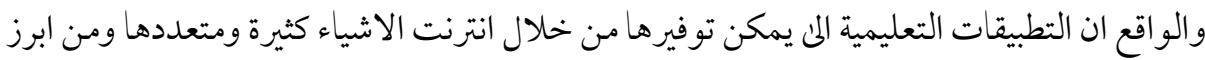

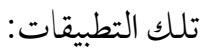

- - لوحات الملصقات التي تطورت باستخدام انترنت الاشياء حيث اصبحت تستخدم

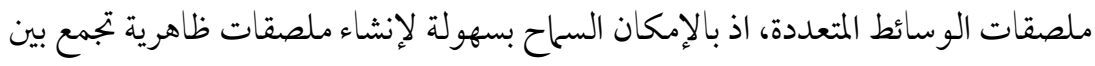
الصور والصوت والفيديو والنص والارتباطات التشعبية، وهذا يسمح لمشاركتها إلكترونيا

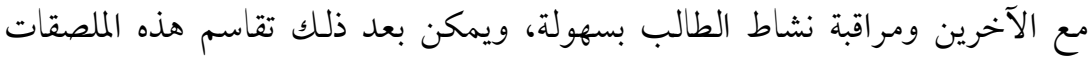
الرقمية مع زملاء الدراسة والمعلمين عبر البريد الإلكتروني.

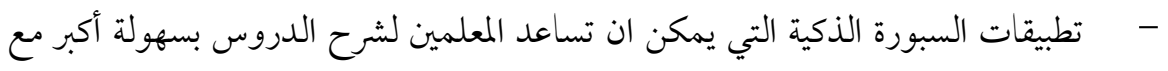

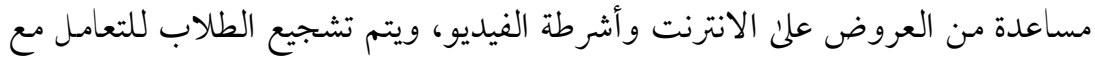

\section{http://dx.doi.org/10.29009/ijres.2.3.1}


الألعاب التفاعلية كمنصة قوية فالأدوات والبرامج القائمة علن الويب تساعد علن تعليم

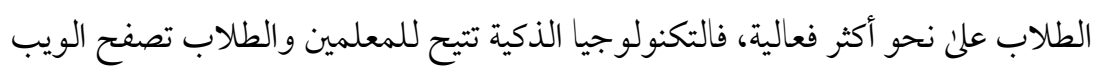
وحتى تعديل مهام الفيديو والمشاركة التفاعلية. - أجهزة المو اتف الذكية وأجهزة الحواسيب اللوحية واجهزة استشعار الحركة فهذه الأجهزة

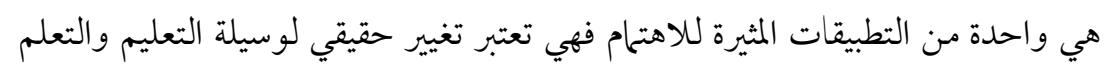

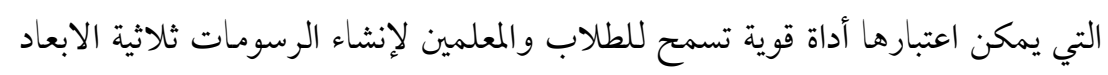

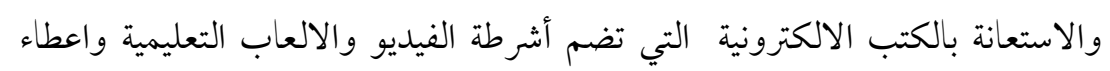

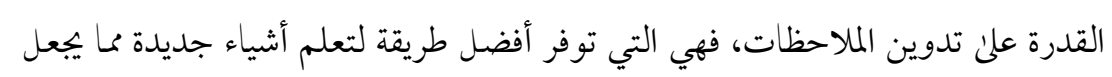

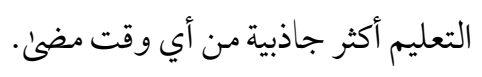

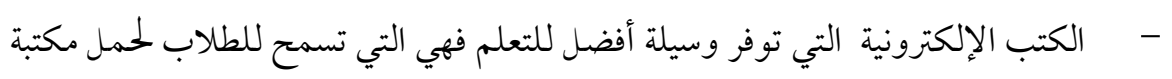
من مئات الكتب معهم بسهولة متضمنة الرسومات البيانية والاشكال ثلاثية الابعاد

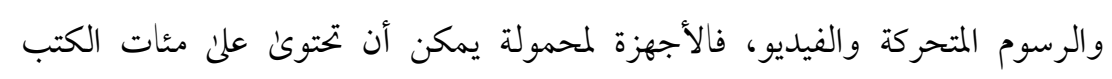

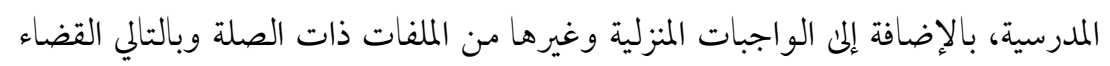

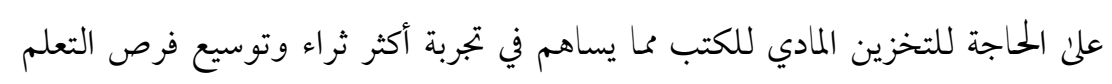
للطلاب. - - تطبيقات أجهزة استشعار درجة الحرارة وتنظيمها بالفصول الدراسية لها تأثير كبير علن

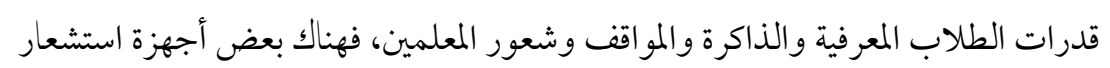

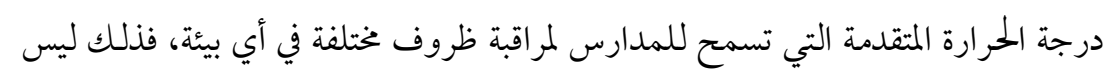

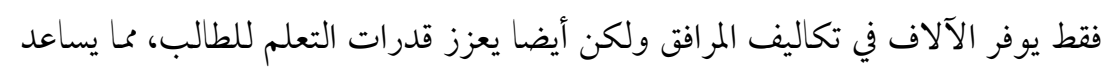
علن مراقبة جميع الفصول الدراسية عن بعد في وقت واحد في أي وقت من أي مكان. 
- - - نظام الحضور المدرسي المبنئ علن انترنت الاشياء الذئ يكفل للمعلمين ادخال المعلومات اللازمة مباشرة في النظام وهذا سوف يساعد علن تقليل الوقت الذي يستغرقه لتقديم بيانات الحضور ويسمح للمسؤولين في المدرسة بإرسال رسالة إلكترونية إلى أولياء الأمور.

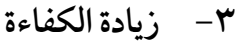

يقضي الطلاب في العديد من المدارس والكليات الكثير من الوقت علن الأنشطة التي لا

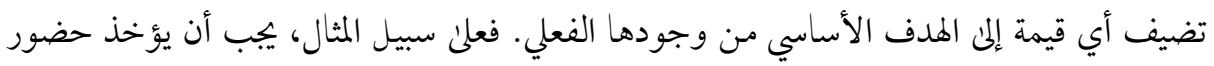

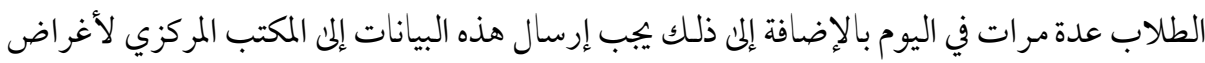
يختلفة. ولكن يمكن لإنترنت الأشياء وضع حد لهذا النظام غير الفعال.

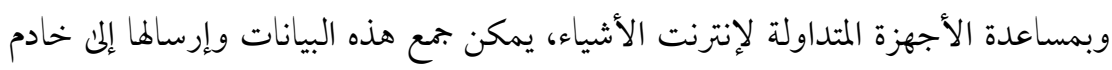

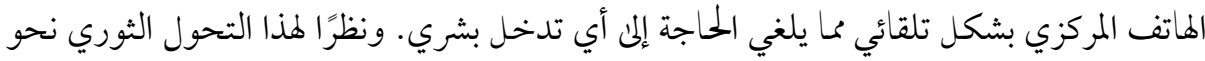

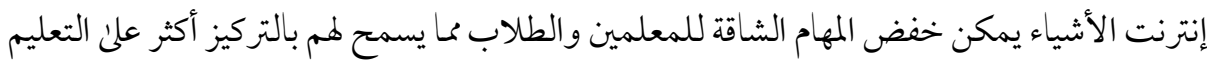
والتعلم. رابعا: التحديات التي تواجه استخدام انترنت الاشياء في بجال التعليم.

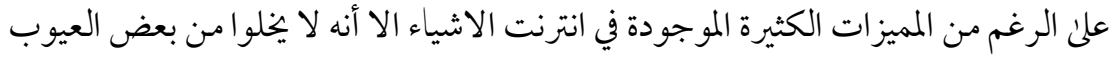

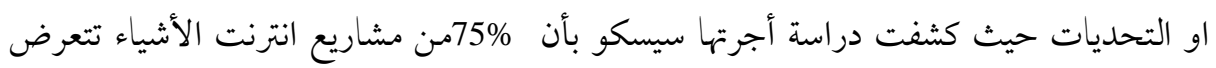

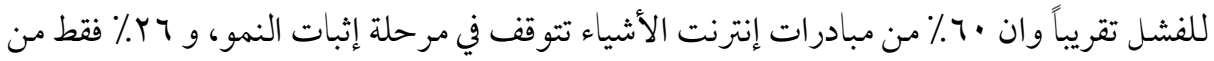

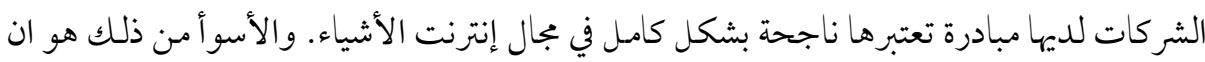

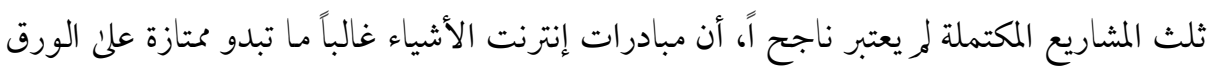

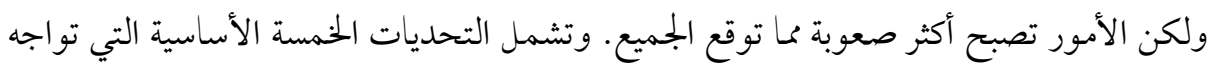

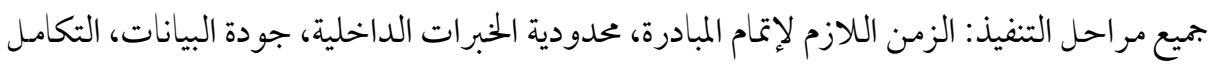

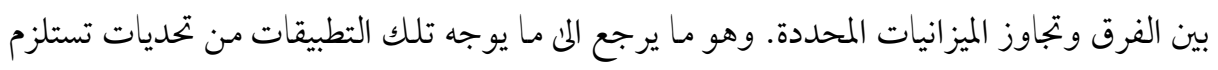

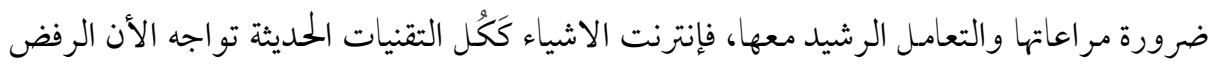

\section{http://dx.doi.org/10.29009/ijres.2.3.1}


التام والانتقادات من قبل البعض، وعدم الثقة علن مستوى الفرد و كذا علن مستوئ الشركات الكبرين و الصغرئ وكذا عدم توافق التقنية مع البنية التحتية المتواجدة حاليا، يمكن إبراز هذه التحديات

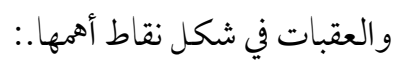

1- الكلفة الاقتصادية: يعتبر الوصول إلى جهاز اتصال رخيص الثمن من أهمّ التحديات التي

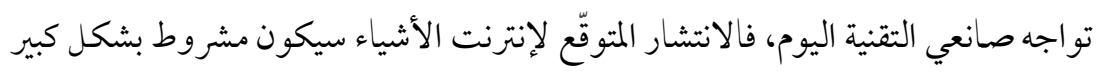
بمدى قدرة الصانعين علن إنتاج جهاز اتصالات غير مكلف وقادر علن التفاعل مع البيئة

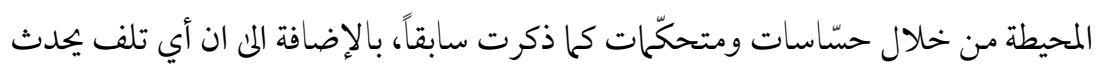
للأنظمة الذكية يمكن ان يحتاج إلى تكاليف مادية باهظة لكي تستطيع اعادة تشغيلها مرة أخرىن r- استهلاك الطاقة: فمعظم أجهزة انترنت الأشياء ستكون محمولة تحتاج لشحن كهربائي بين الحين والآخر وهذا يضع عبء إضافي علن المستخدم، ولهذا يأمل الباحثون بتطوير تقنيات الجيل الخامس بحيث تستهلك أقل طاقة ممكنة مع الحفاظ علن جودة ووثوقية الاتصال. وربّّا قد يساعد كذلك الوصول مستقبلاً إلى نقل مقادير قليلة من الطاقة بشكل لاسلكي ضمن بجال يصل إلى عدّة أمتار. الأمان والموثوقية: ثاني أهم العوامل التي ستؤثر بمدئ انتشار انترنت الأشياء هو الموثوقية التي لتي

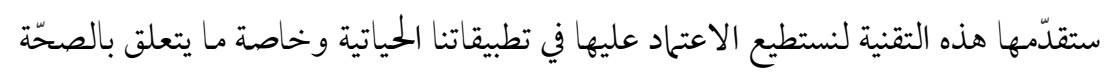
والأمن، حيث يمكن ببساطة لأي مخترق ذبذبة الأمن من خلال التلاعب بعدادات

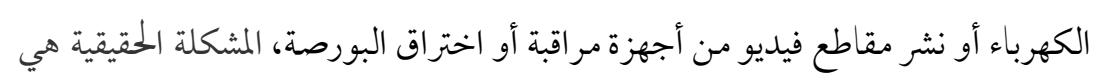

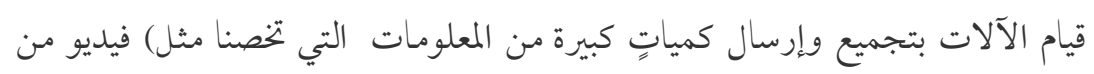
داخل المنزل، مواقعنا ونشاطاتنا، حالتنا الصحية (من المحتمل أن هناك أشخاصا يستطيعون اختراق وسرقة هذه البيانات للتجسس علينا أو تخريب النظام. 
ب- المعايرة :Standardisation لا زال النقاش قائماً حول الحاجة إلى وجود معيار شامل وأوحد لإنترنت الأشياء، البعض يرفض ذلك والآخر يؤمن أنه حتمي في حين أنّ يقترح وسطيون وجود عدّة معايير مرنة وغير مقيّدة بدقّة كاملة في هذه التقنية. ع- - الخصوصية: فمن أهم التحديات التي تجابه تطوير انترنت الأشياء هو الحرص على خصوصية المستخدمين وضمان سرّية معلوماتهم الشخصية كاملةً، حيث يمكن اختراق نظام هذه الأشياء وانتهاك الخصوصية والعبث بها من طرف الهاكر سواء من أجل التسلية فقط أو من اجل اغراض اقتصادية واجتماعية وحتىل سياسية، فمعظم الأجهزة الذكية تعمل بنظام التجسس علن العملاء وجمع بيانات شخصية عنهم، ومعرفة الأمور التي يفكروا بها، وهذة الاجهزة يمكن اختراقها ببساطة من خلال البيانات التي يتم جمعها عنك واستغلالها بشكل سيء، وهو أمر له بعد اجتماعي عميق في السوق كون هذا العامل قد يدفع المستخدم للإحجام عن استخدام التقنية بشكل واسع، وكمثال مشابه جداً لعلّ القارئ يستذكر شركة سامسونغ العام الماضي وهي تحذر مستخدمي تلفزيوناتها الذكية من التحدّث أمـامها بأحاديث شخصية لأنها تحوي ميزة الأوامر الصوتية التي تنقل ما يلتقهه المايكروفون إلى شبكة الانترنت بشكل دائم. 0- قصور التشريعات حيث يستدعي تطبيق بعض التقنيات التي تمنح المجتمع خدمات ثورية شاملة سنّ قوانين ملائمة لتستوعب أثر هذه الخدمات في بعدها الاجتماعي العميق. على سبيل المثال، حين ظهرت خدمة مكالمات الفيديو والهو اتف ذات الكاميرات احتدم النقاش القانوني عن مدى اعتبار هذه المكالمات انتهاكاً لخصوصية مستخدميها أو عن إمكانية التنصّت عليها أو اعتبارها دلائل قانونية تصلح في المحاكم. في حالة انترنت الأشياء المشكلة أكبر وأعقد، فمثلاً من سيتحمل المسؤولية القانونية حين يحدث خطأ ما في هذه التقنية يؤدي

$$
\text { إلنى حادث مروري أو ضرر شخصي أو حتّى معنوي؟. }
$$


7- التحديات الاجتمعية والصحية والنفسية: فاعتماد الاشخاص علن التكنولوجيا التي تقوم

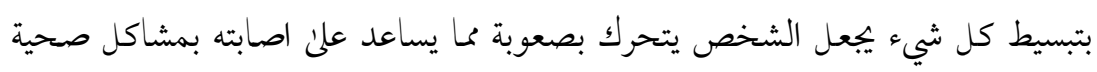

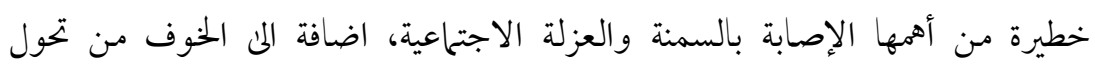

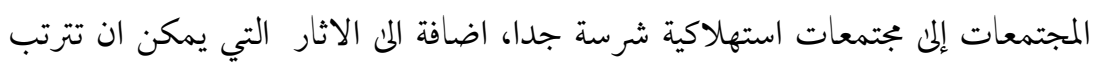

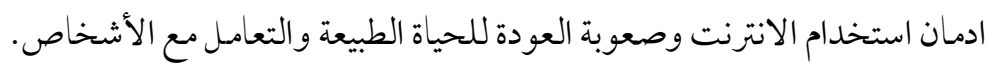

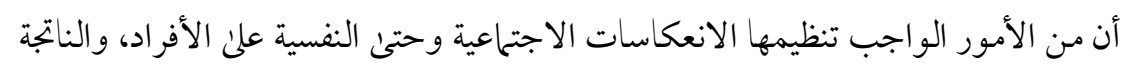

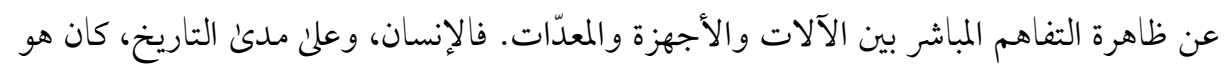

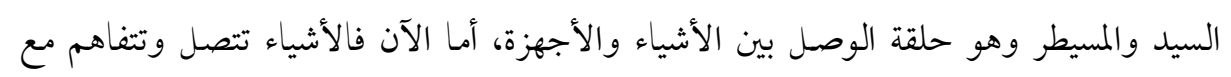

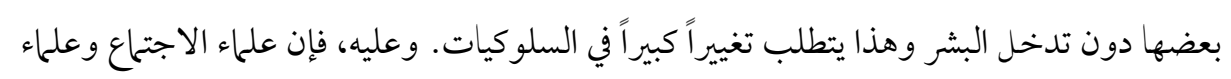
النفس ومن في حكمهم مدعوون لكي يعطوا هذا الموضوع أهيمته التي يستحقها.

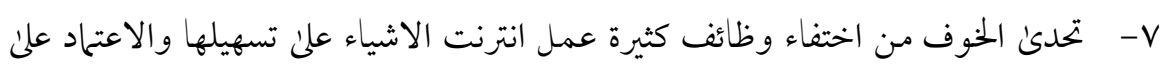

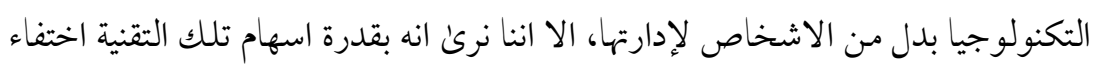

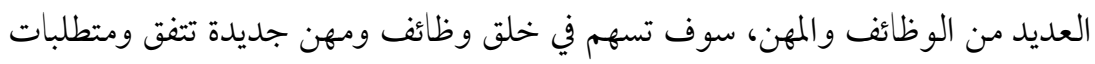
تلك التقنية. ^- تحدئ البيانات الكبيرة: 'حيث أدت كثرة الاشياء المتصلة بالإنترنت المن وجود كميات كبيرة

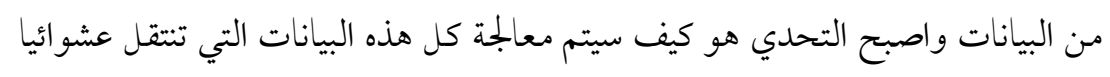

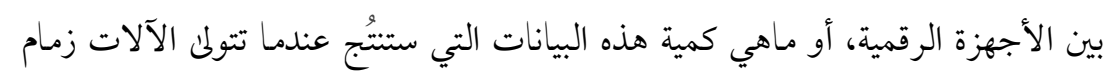

هIG DATA أداة واحدة فقط من أدوات إدارة قواعد البيانات أو باستخدام تطبيقات معالجة البيانات التقليدية. حيث تشمل التحديات ،الالتقاط،

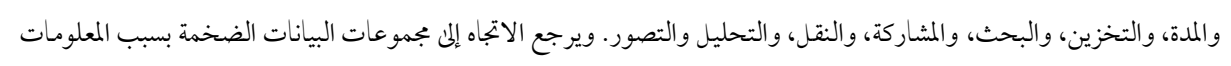

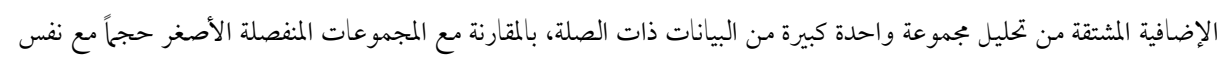

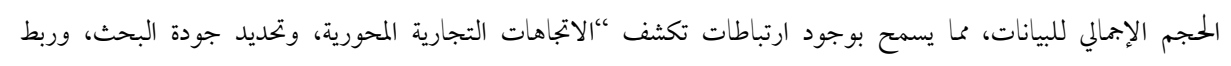

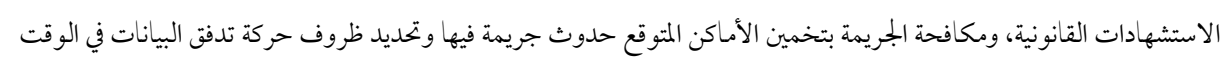


الأمور، طبعا ستكون بحجم خر افي لم يسبق للعالم الرقمي التعامل معها، فقد أدى استخدام أدوات التعلم عبر الإنترنت والبرامج القائمة علن التفاعل بصورة متزايدة في بجال التعليم إلى زيادة حجم البيانات، فأصبح من الصعب تحليل واستخدام تلك البيانات الضخمة لتحسين الفعالية التعليمية ودعم البحوث الأساسية بشأن التعلم، واصبحنا في حاجة إلى استحداث طرق جديدة وفعالة لتحليل هذا الكم الهائل من المعلومات والاستفادة منها في تحسين العملية التعليمية وتطوير الأبحاث في مجال التعليم، وهو ما يعرف بعلم المعلومات (Data science) كانت منظمة أو غير منظمة، و يعتبر تمديدا لمجال تنقيب البيانات (Data mining) و التحليلات التنبؤية (Predictive analytics).

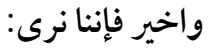

- ان تطبيقات إنترنت الأشياء في الحياة المعاصرة اصبحت ضرورية بل وحتمية لا سيا في قطاع التعليم، وهذه التطبيقات تتطلب وجود بنى تحتية وشبكات اتصال لاسلكية مرنة، وليتوافق مع استخدام أجهزة إنترنت الأشياء والوصول إليها تحتاج شبكات الاتصال اللاسلكية إلى العمل كمنصة تربط أجهزة إنترنت الأشياء معاً، كما تحتاج مثل هذه الشبكات إتهرة إلى نقاط وصول قوية لتجنب قيود عرض النطاق الترددي خاصةً في المناطق ذات الكثافة العالية من المستخدمين. - - من الضروري العمل علن زيادة الوعي بأهمية دور إنترنت الأشياء في تطوير خدمات مؤسسات التعليمية، وتخصيص المزيدمن حلقات النقاش والندوات المتخصصة في موضوع خدمات إنترنت الأشياء لاكتشاف المزيد من الفرص الواعدة، ودراسة مكامن القلق التي تهدد استثمار تطبيقات انترنت الأشياء في أعمال وخدمات المؤسسات التعليمية. - - العمل علن تطوير قدرات الذكاء الصناعي والاستفادة الثورة الصناعية الرابعة بها ساهم في الزيادة الحقيقة للأشياء المتصلة بالإنترنت وكذلك الأجهزة المزودة بمستشعرات التي 
يرتديها البشر لتحدد هو ياتهم وعنوانهم والتي انتجت وسوف تتتج كما هائلاً من البيانات

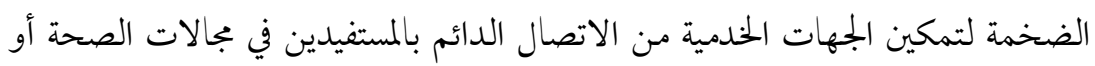
التعليم والخدمات الأخرىن، والأهم من ذلك في هذا المقام خدمات مؤسسات التهات التعليم.

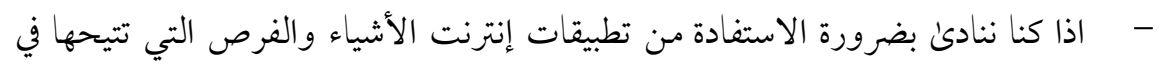

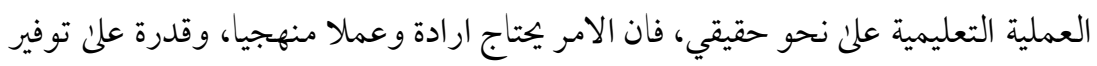

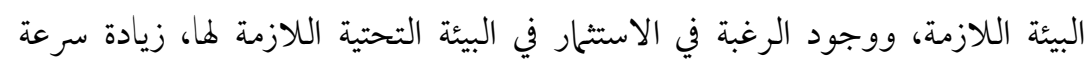

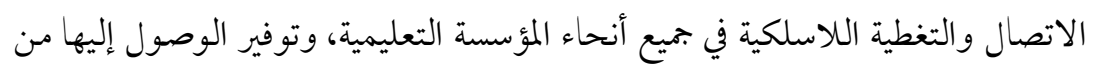

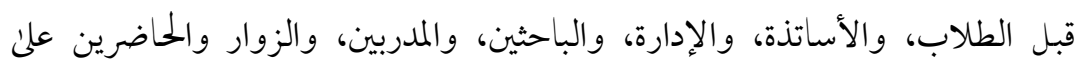

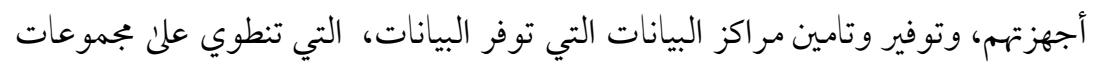

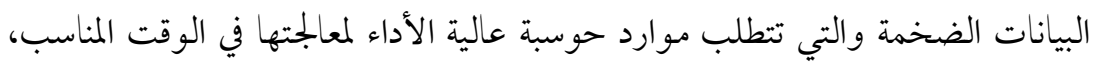

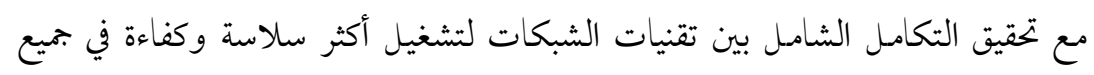
أنحاء النظام في المؤسسة التعليمية.

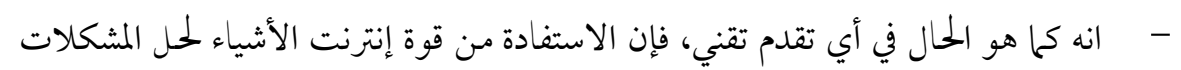

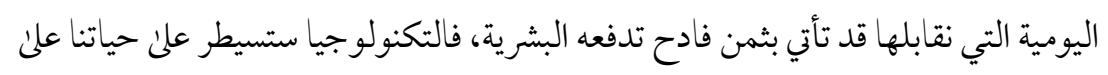
نحو متزايد، ونحن بالفعل في قلب هذه المرحلة حيث تسيطر التكنولوجيا علن حياتنا،

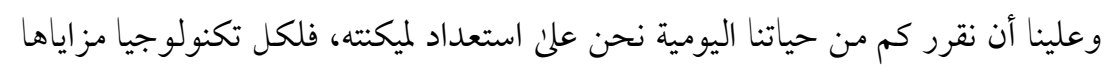

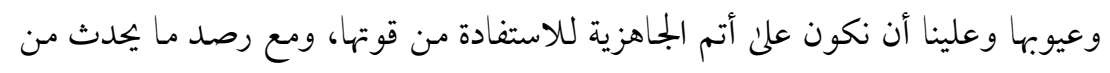

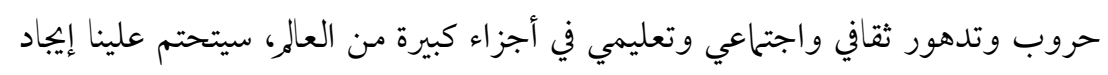

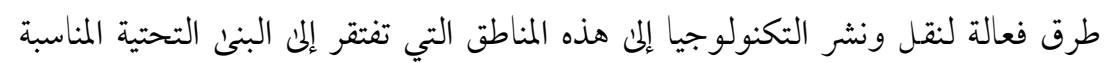

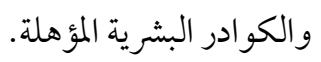


1. امحد، فرج. (Y) (Y). استثار تقنيات انترنت الأشياء لتعزيز آليات الوعي المعلوماتي في مؤسسات المعلومات: دراسة تخطيطية- منشور في المؤتمر TV للاتحاد العربي للمكتبات

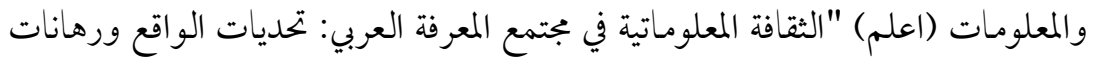

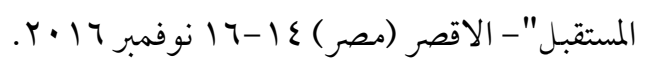

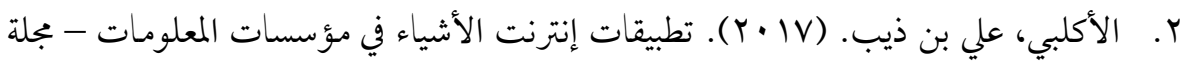

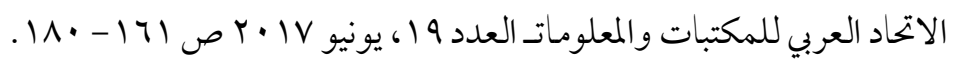

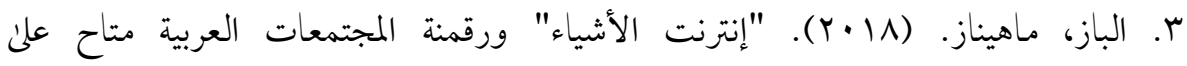
/http://aitmag.ahram.org.eg/News/101875

ع. بدوي، محمود فوزي أحمد. (9 ا ·r). "رؤية مستقبلية لتطوير التعليم الجامعي المصري في ضوء

الوظائف المتوقعة لسوق العمل" بحث مرجعي مقدم إلم:اللجنة العلمية الدائمة لترقية

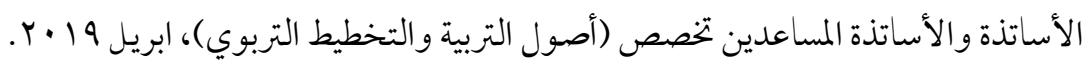

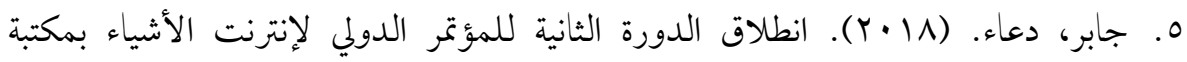

الإسكندرية

https://iskandarany.weladelbalad.com/2018/12/04/\%D8\%BA\%D8\%AF\%D9 1\%8B\%D8\%A7-\%D8\%A7\%D9\%86\%D8\%B7\%D9\%84\%D8\%A7\%D9\%82 T. الجعيد، عبدالرمن عويض. (1) • (Y). تحليل البيانات الكبيرة Big Data وتحسين التعليم متاح https://www.new-

علن

educ.com/\%D8\%A7\%D9\%84\%D8\%A8\%D9\%8A\%D8\%A7\%D9\%86\%D8 \%A7\%D8\%AA-

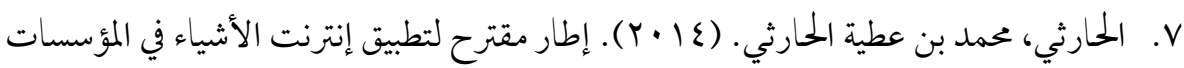
التعليمية- بجلة الدراسات التربوية والانسانية كلية التربية جامعة دمنهور المجلد السادس،

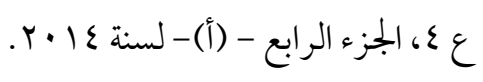

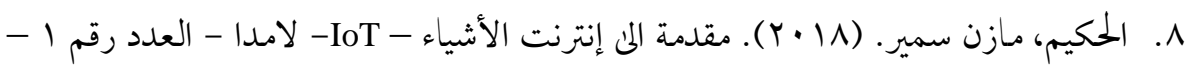

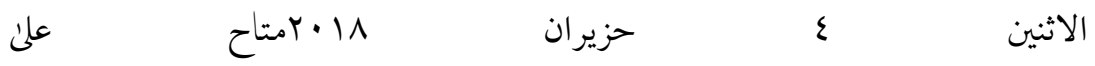


https://www.researchgate.net/publication/325645682_IoT_mqdmt_aly_antrnt _alashya?fbclid=IwAR3kmlUHyMgT

9. الحمامي، علاء حسين؛ الحكيم، مازن سمير. (17 (Y). كل شيء عن انترنت الاشياء وتطبيقات المدن الذكية - دار الراية للنشر - عمان - الاردن - ايار 7 • ب.

• اـ الدهشان، جمال علن.. (9 (r). إنترنت الأشياء: ثورة التكنولوجيا المرتقبة وحاجتنا الما

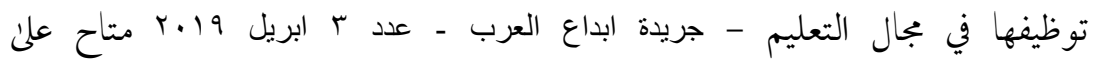
http://ebdaelarab.com/2019/04/03/\%d8\%a5\%d9\%86\%d8\%aa\%d8\%b1\%d9\% $86 \% \mathrm{~d} 8 \%$ aa-

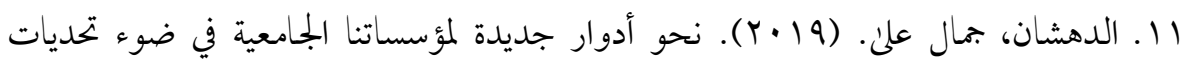
http://pressst.com/?p=30002 ومتطلبات العصر الرقمي متاح على

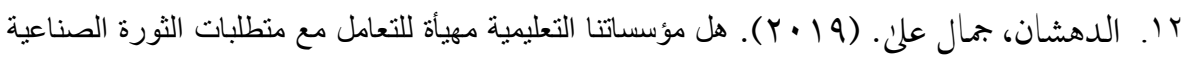

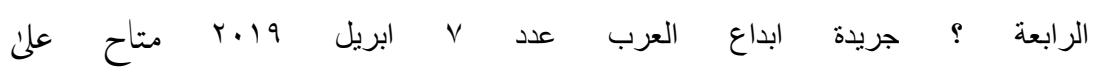
http://ebdaelarab.com/2019/04/07/\%D9\%87\%D9\%84\%D9\%85\%D8\%A4\%D8\%B3\%D8\%B3\%D8\%A7\%D8\%AA\%D9\%86\%D8 $\%$ A7-

rا ـ رافيندرا، سافارام. (N) (Y). دور إنترنت الأشياء في مجال التعليم - ترجمة: سندس مكحل | https://www.threadsnj.com/single-post/role-of- تدقيق: لطيفة المهيني- متاح على iot-in-education

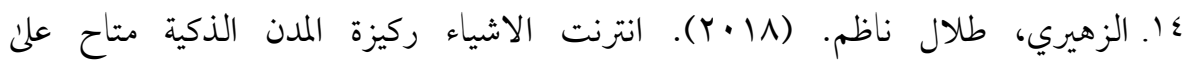
https://drtazzuhairi.blogspot.com/2016/12/blogpost_19.html?fbclid=IwAR1yIV_Hgc16t3HWWDyn6iX6jTiZ99OxF9zY9I DIZV3kK0pPjNdmzI9Eo40

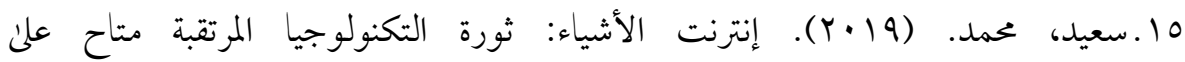
https://www.noonpost.com/content/14574

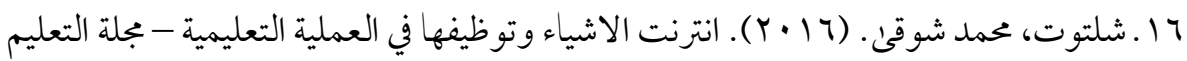

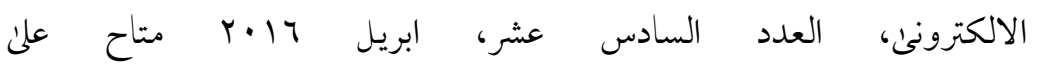
http://emag.mans.edu.eg/index.php?page=news\&task=show\&id=517

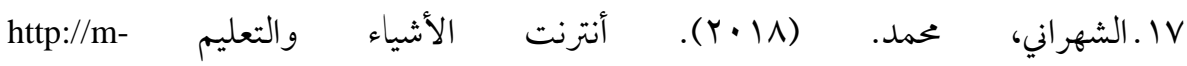
shahrani.com/iot/?fbclid=IwAR3EbDK5c7C3ijoYTRuTjBNbJV3SaKcwkqF yHMbMK9JzArtanYK7K5uDNho 


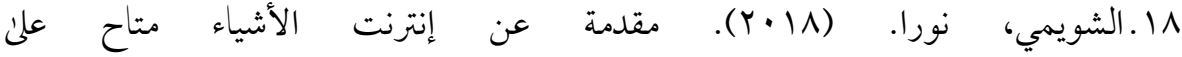
https://www.egyres.com/articles/\%D8\%A5\%D9\%86\%D8\%AA\%D8\%B1\% D9\%86\%D8\%AA-

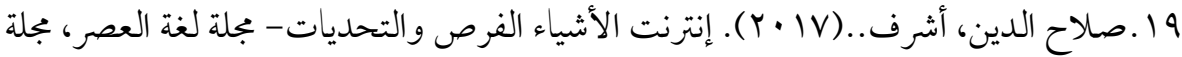

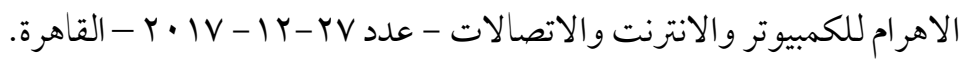

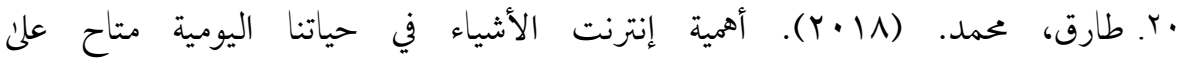
https://vapulus.com/blog/ar/\%d8\%a7\%d9\%87\%d9\%85\%d9\%8a\%d8\%a9$\%$ d8\%a5\%d9\%86\%d8\%aa\%d8\%b1\%d9\%86\%d8\%aa$\% \mathrm{~d} 8 \% \mathrm{a} 7 \% \mathrm{~d} 9 \% 84 \% \mathrm{~d} 8 \% \mathrm{a} 3 \% \mathrm{~d} 8 \% \mathrm{~b} 4 \% \mathrm{~d} 9 \% 8 \mathrm{a} \% \mathrm{~d} 8 \% \mathrm{a} 7 \% \mathrm{~d} 8 \% \mathrm{a} 1-$ ا.Y.ظريفة، نضال. (1) (Y). الطريق إلى الجيل الخامس - التطبيق الأهم: إنترنت الأشياء متاح https://ardroid.com/author/nidal على r r. عبد العال، عبد الناصر. (1) (Y). (إنترنت الأشياء)" تتوّج المعلوماتيّة ملكة العلوم في القرن http://www.alhayat.com/article/750774/-

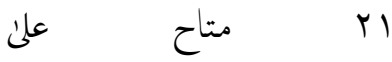
\%D8\%A5\%D9\%86\%D8\%AA\%D8\%B1\%D9\%86\%D8\%AAr r. عبد العزيز، احد. (1) • (Y). استخدام تكنولو جيا إنترنت الأشياء داخل جامعة الإسكندرية -

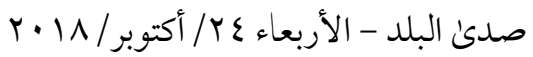
ع r.عياد، مؤمن فضل. (1) • ( ). إنترنت الأشياء ( IOT ): الثورة التكنولوجية التي غيرت مفهوم https://www.paldf.net/forum/showthread.php?t=1 الإنترنت متاح على 190573 Introduction to الطيف، مصطفي صادق. (Y) (Y). كتاب )مدخل النى انترنت الاشياء https://static-course- الجزء الاول متاح على - Internet of Things IoT assets.s3.amazonaws.com/I2IoT13/en/index.html

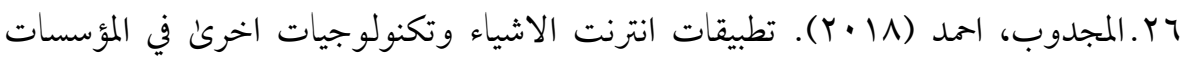

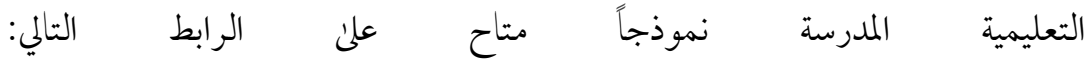
https://www.eanlibya.com/\%D8\%AA\%D8\%B7\%D8\%A8\%D9\%8A

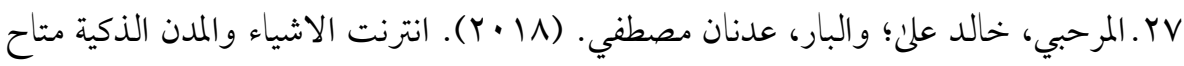
https://www.alfaisal-scientific.com/?p=2205 على 
A.r. مكاوي، مرام عبدالرحمن. (19 (Y). الذكاء الاصطناعي علن أبواب التعليم متاح علن https://qafilah.com/\%D8\%A7\%D9\%84\%D8\%B0\%D9\%83\%D8\%A7\%D8\%

A1-

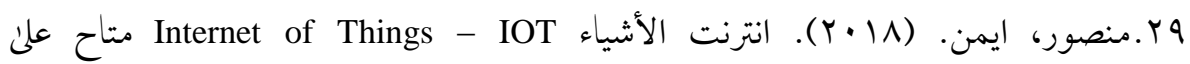
https://www.facebook.com/DrAymanMansourMurad/posts/\%D8\%A3\%D9\% 86\%D8\%AA\%D

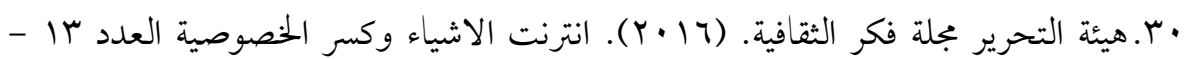

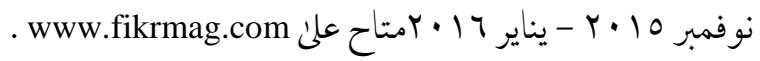




\section{References}

Abdel-Al, Abdel Nasser. (2018). «Internet stuff» culminates informatics Queen of

Science in the 21st century Available at http://www.alhayat.com/article/750774/\%D8\%A5\%D9\%86\%D8\%AA\%D8\%B1\%D9\%86\%D8 \% AA

Abdul Aziz, Ahmed. (2018). The use of Internet technology objects within the University of Alexandria - Echo of the country - Wednesday 24 October 2018 Advanced Electronics Company: THE INTERNETOF THINGS AND THE ENTERPRISES http://www.aecl.com/AECWeb/media/Assets/WhitePapers/TheInternet-of-Things-and-the-Enterprise-09.pdf?ext=.pdf Ahmad Faraj. (2016). - Information Technologies in the Arab Knowledge Society: The .Challenges of Reality and Future Bets - Luxor (Egypt), 14-16 November 2016 Al-Aslbi, Ali bin Dhib. (2017). Internet Applications in Information Institutions Journal of the Arab Union for Libraries and Information, No. 19, June 2017, pp.

Al-Dahshan, Jamal Ali. (2019). Are our educational institutions ready to deal with the requirements of the Fourth Industrial Revolution? Al-Arabiya Newspaper No. 7 April 2019 Available at http://ebdaelarab.com/2019/04/07/\%D9\%87\%D9\%84\%D9\%85\%D8\%A4\%D8\%B3\%D8\%B3\%D8 \% A7\% D8\% AA\% D9\% 86\% D8\%

\section{A7-}

Al-Dahshan, Jamal Ali. (2019). Internet things: the upcoming technology revolution and our need to employ them in the field of education - Newspaper Arab creativity $\begin{array}{llll}\text { number } & 3 & \text { April } & 2019\end{array}$ http://ebdaelarab.com/2019/04/03/\%d8\%a5\%d9\%86\%d8\%aa\%d8\% b1\% d9\% 86\% $\mathrm{d} 8 \%$ aa

Al-Dahshan, Jamal Ali. (2019). Towards new roles for our university institutions in light of the challenges and requirements of the digital age is available at http://pressst.com/?p=30002

Al-Hamami, Alaa Hussein; Hakim, Mazen Samir. (2016). All about Internet stuff and .smart city applications - Dar Al Raya Publishing - Amman - Jordan - May 2016 Al-Harthy, Mohammed bin Attia Al-Harthy. (2014). A Proposed Framework for the Application of Internet in Educational Institutions - Journal of Educational and 
Human Studies, Faculty of Education, University of Damanhur Vol. VI, P4, Part IV

$$
\text { - (a) - } 2014
$$

Aljaid, Abdul Rahman Oweid. (2018). Big Data Analysis and Education Improvement is available at https://www.neweduc.com/\%D8\%A7\%D9\%84\%D8\%A8\%D9\%8A\%D8\%A7\%D9\%86\%D8\%A7\%

$\mathrm{D} 8 \%$ AA

Al-Majdoub, Ahmed (2018). Applications Internet stuff and other technologies in educational institutions School model is available at the following link: https://www.eanlibya.com/\%D8\%AA\%D8\%B7\%D8\%A8\%D9\%8A

Al-Morbi, Khaled Ali; Al-Bar, Adnan Mustafa. (2018). Internet Smart Things and Cities is available at https://www.alfaisal-scientific.com/?p=2205

Ashton, K. (2012). “That 'internet of things' thing in the real world, things matter more than ideas," RFID Journal, https://www.rfidjournal.com/articles/view?4986 Ayad, Mo'men Fadl. (2018). Internet Things (IoT): The technological revolution that changed the concept of the Internet is available at https://www.paldf.net/forum/showthread.php?t=1190573

Badawi, Mahmoud Fawzi Ahmed. (2019). "A Future Vision for the Development of Egyptian University Education in the Light of the Expected Jobs of the Labor Market" Reference Paper Submitted to: Permanent Scientific Committee for the Promotion of Professors and Associate Professors (Specialization of Education and .Educational Planning), April 2019

Baz, Mahinaz. (2018). "Internet Things" and digitizing Arab societies is available at http://aitmag.ahram.org.eg/News/101875/

Editorial Board Fikr Cultural Magazine. (2016). Internet stuff and privacy break Issue 13 - November 2015 - January 2016 Available at www.fikrmag.com.

Hakim, Mazen Samir. (2018). Introduction to Internet Things - IoT-Lambda - Issue 1 Monday June 4, 2018 Available at https://www.researchgate.net/publication/325645682_IoT_mqdmt_aly_antrnt_alash ya?fbclid=IwAR3kmlUHyMgT Hung, M. (2017). Leading the IoT [PDF]. Gartner. International Telecommunications Union: Overview of The Internet of Things [PDF]. 
Jaber, Duaa. (2018). The Second Session of the International Conference on Internet Objects at the Bibliotheca Alexandrina - December 2018 is available at https://iskandarany.weladelbalad.com/2018/12/04/\%D8\%BA\%D8\%AF\%D9\%8B\% 8\%A7-\%D8\% A7\% D9\% 86\% D8\% B7\% D9\% 84\% D8\% A7\% D9\% 82 /

Latif, Mustafa Sadek. (2018). Book) Introduction to Internet Stuff Introduction to Internet of Things IoT - Part 1 Available at https://static-courseassets.s3.amazonaws.com/I2IoT13/en/index.html

Makkawi, Maram Abdul Rahman. (2019). Artificial intelligence on education doors is available

https://qafilah.com/\%D8\%A7\%D9\%84\%D8\%B0\%D9\%83\%D8\%A7\%D8\%A1-

@Malia Keirsey: How Will the Internet of Things Impact Education https://datafloq.com/read/author/malia-keirsey/3380

Mansour, Ayman. (2018). Internet of Things - IOT is available at https://www.facebook.com/DrAymanMansourMurad/posts/\%D8\%A3\%D9\%86\%D $8 \% \mathrm{AA} \% \mathrm{D}$

Mikkie Mills: The Future of the Education System lies in the Internet of Things https://datafloq.com/read/future-education-system-internet-of-things/6020

Ravindra, Safaram. (2018). The Role of Internet Things in Education Check out: Latifa Mahini - available at https://www.threadsnj.com/single-post/role-of-iot-ineducation

Sadness, struggle. (2018). The way to the fifth generation - the most important application: Internet things available at https://ardroid.com/author/nida

Said Mohamed. (2019). Internet Things: The upcoming technology revolution is available at https://www.noonpost.com/content/14574

Salah Eddin, Ashraf. (2017). Internet Things Opportunities and Challenges - Journal of the Age Language, Al-Ahram Journal of Computer, Internet and Communications -

.No. 27-12- 2017 - Cairo

Shahrani, Mohammed. (2018). Internet things and education http://mshahrani.com/iot/?fbclid=IwAR3EbDK5c7C3ijoYTRuTjBNbJV3SaKcwkqFyHMb

MK9JzArtanYK7K5uDNho 
Shaltout, Mohamed Shawky. (2016). Internet stuff and employment in the educational process - Journal of e-learning, the sixteenth issue, April 2016 is available at http://emag.mans.edu.eg/index.php?page=news\&task=show\&id=517

Shouimi, Nora. (2018). Introduction to Internet Things is available at https://www.egyres.com/articles/\%D8\%A5\%D9\%86\%D8\%AA\%D8\%B1\%D9\%86 $\%$ D8\%AA-

Tarek, Mohamed. (2018). The importance of Internet things in our daily lives is available

https://vapulus.com/blog/en/\%d8\%a7\%d9\%87\%d9\%85\%d9\%8a\%d8\%a9$\% \mathrm{~d} 8 \%$ a5\% $9 \% 86 \%$ d8\% aa\% d8\% b1\% d9\% $86 \%$ d8\% aa\% d8\% a7\% d9\% 84\% $\mathrm{d} 8 \%$ a3\% d8\% b4\% d9\% $8 \mathrm{a} \% \mathrm{~d} 8 \%$ a7\% d8\% a1 Zuhairi, Talal Nazem. (2018). Internet stuff Smart City Base is available at https://drtazzuhairi.blogspot.com/2016/12/blogpost_19.html?fbclid=IwAR1yIV_Hg c16t3HWWDyn6iX6jTiZ99OxF9zY9IDIZV3kK0pPjNdmzI9Eo40 